\author{
Supporting Information
}

\title{
Porphyrinic Silver Cluster Assembled Material for Simultaneous Capture and Photocatalysis of Mustard- Gas Simulant
}

Man Cao,${ }^{\dagger}$ Rui Pang,, Qian-You Wang $, *, \dagger^{*}$ Zhen Han,${ }^{\dagger}$ Zhao-Yang Wang,${ }^{\dagger}$ Xi-Yan Dong, ${ }^{\dagger}$ Shun-Fang Li,, Shuang-Quan Zang, ${ }^{*, \dagger}$ and Thomas C. W. Mak ${ }^{\dagger}, \S$

${ }^{\dagger}$ College of Chemistry and Molecular Engineering, Zhengzhou University, Zhengzhou 450001, China International Laboratory for Quantum Functional Materials of Henan and School of Physics and Engineering, Zhengzhou University, Zhengzhou 450001, China

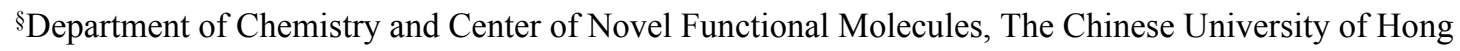
Kong, Shatin, New Territories, Hong Kong SAR, China

E-mail: zangsqzg@zzu.edu.cn; qianyouwang@zzu.edu.cn 


\section{Contents:}

Part S1. General Information.........................................................................................S3

Part S2. Synthetic Procedure...........................................................................................S4

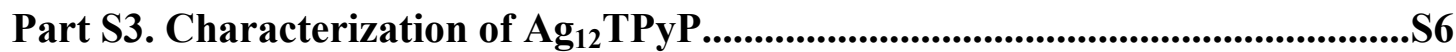

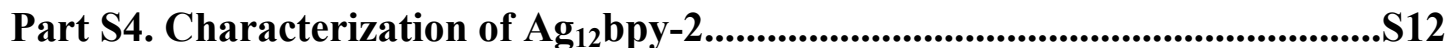

Part S5. Detection of ${ }^{1} \mathrm{O}_{2}$ Generation.........................................................................S14

Part S6. Capability of $\mathrm{Ag}_{12} \mathrm{TPyP}$ to capture CEES..................................................S18

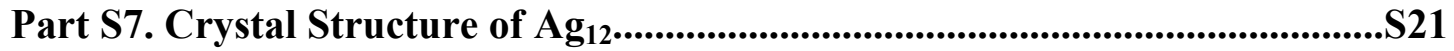

Part S8. Catalytic Studies..................................................................................522

Part S9. Comparison of CEES degradation efficiency using MOF-based photosensitizers for singlet oxygen production........................................S28

Part S10. Vienna ab initio simulation package (VASP) calculations........................S29 


\section{Part S1. General Information}

\section{Materials and Reagents}

All chemicals and solvents obtained from suppliers were used without further purification. $\mathrm{AgS}^{t} \mathrm{Bu}$ was obtained by adding equivalent amounts of $\mathrm{Ag}_{2} \mathrm{O}$ and $\mathrm{HS} \mathrm{Bu}^{\mathrm{t}}$ in the presence of $\mathrm{Et}_{3} \mathrm{~N}$.

\section{Measurements}

${ }^{1} \mathrm{H}$ NMR and ${ }^{13} \mathrm{C}$ NMR spectra were recorded on a Bruker DRX spectrometer operating at $400 \mathrm{MHz}$. Single-crystal X-ray diffraction (SCXRD) was performed on a Rigaku XtaLAB Pro diffractometer using $\mathrm{Cu} \mathrm{K \alpha}$ radiation $(\lambda=1.54184 \AA)$. Powder Xray diffraction (PXRD) were collected on a Riguku D/Max-2500PC X-ray diffractometer with $\mathrm{Cu}$ sealed tub $(\lambda=1.54178 \AA)$. X-ray photoelectron spectroscopy (XPS) were obtained on a Thermo ESCALAB 250XI electron spectrometer using 300 $\mathrm{W} \mathrm{Al} \mathrm{K}_{\alpha}$ radiation. The $\mathrm{C}$ peak at $284.6 \mathrm{eV}$ was used as a reference to correct for charging effects. The photoluminescence (PL) emission spectra were measured by using a Horiba FluoroLog-3 spectrofluorometer. Elemental mapping analyses were carried out using Zeiss Sigma 500 on a scanning electron microscopy (SEM) measurement. Singlet oxygen was generated from Perfect Light PCX-50A Discover (power density was $80 \mathrm{~mW} / \mathrm{cm}^{2}$ ). UV-vis diffuse reflectance data was recorded with a Hitachi UH4150 spectrophotoreter. Electron paramagnetic resonance (EPR) were recorded on Bruker BioSpin EMX plus electron paramagnetic resonance spectrometer at liquid nitrogen in the absence or presence of Xe light irradiation. The adsorption isotherms of $\mathrm{N}_{2}$ and $\mathrm{O}_{2}$ were measured by a volumetric method using a Beishide $3 \mathrm{H}$ 2000PM2 physisorption analyzer at $77 \mathrm{~K}$. The adsorption isotherm of CEES at $298 \mathrm{~K}$ were measured by gravimetric method using a Beishide 3H-2000PW Adsorption Analyzer. After as-obtained $\mathrm{Ag}_{12} \mathrm{TPyP}$ was vacuum degassed at room temperature, the adsorption amounts of CEES evaporated into it were monitored by recording the sample mass while altering the pressure. 


\section{Part S2. Synthetic procedure}

\section{Synthesis of $\operatorname{Ag}_{12}$ TPyP single crystals}

$\mathrm{AgS}^{t} \mathrm{Bu}(0.10 \mathrm{~g}, 0.5 \mathrm{mmol})$ and $\mathrm{CF}_{3} \mathrm{COOAg}(0.11 \mathrm{~g}, 0.5 \mathrm{mmol})$ were dissolved in a mixed solvent of acetonitrile and 1,4-dioxane $(1: 1,30 \mathrm{~mL})$ under stirring for $2 \mathrm{~min}$. Then, $10 \mathrm{~mL}$ of a trichloromethane solution containing TPyP $(0.01 \mathrm{~g}, 0.016 \mathrm{mmol})$ and $\mathrm{CF}_{3} \mathrm{COOH}(50 \mu \mathrm{L}, 3 \mathrm{mmol})$ was added under stirring and was subsequently filtered. The filtrate was slowly evaporated in air to give dark-purple crystals of $\mathbf{A g}_{\mathbf{1 2}} \mathbf{T P y} \mathbf{P}$ (71.65\% yield based on TPyP). Elemental analysis (\%) for evacuated $\mathbf{A g}_{12} \mathbf{T P y} \mathbf{P}$ $\left(\mathrm{C}_{76} \mathrm{H}_{80} \mathrm{Ag}_{12} \mathrm{~F}_{18} \mathrm{~N}_{8} \mathrm{O}_{12} \mathrm{~S}_{6}, \mathrm{M}=3126.27\right)$ : calcd. C: 29.20, H: 2.58, N: 3.58, S: 6.15; found C: 29.44, H: 2.56, N: 3.18, S: 5.96 .

\section{Synthesis of $\mathbf{A g}_{12} \mathrm{bpy}-2$ single crystals}

$\mathrm{Ag}_{12}$ bpy-2 single crystals were synthesized according to a previous report, which comprised the same $\mathrm{Ag}_{12}$ core structure as $\mathrm{Ag}_{12} \mathrm{TPyP}$. $\mathrm{S} 1$

$\mathrm{AgS}{ }^{t} \mathrm{Bu}(0.02 \mathrm{~g}, 0.1 \mathrm{mmol})$ and $\mathrm{CF}_{3} \mathrm{COOAg}(0.022 \mathrm{~g}, 0.10 \mathrm{mmol})$ were dissolved in a mixed solvent of DMAc and toluene $(2: 1,3 \mathrm{~mL})$ under stirring for $5 \mathrm{~min}$. Then, 1 $\mathrm{mL}$ DMAc solution containing 4,4'-bipyridine $(7.8 \mathrm{mg}, 0.05 \mathrm{mmol}$ ) was added dropwise. After the mixture was allowed to stand for several hours, and colorless blocklike hexagonal crystals were deposited.

\section{Synthesis of $\mathrm{Ag}_{12}$ single crystals}

$\mathrm{Ag}_{12}$ DMAP (denoted as $\mathrm{Ag}_{12}$ ) single crystals were synthesized according to a previous report. ${ }^{\mathrm{S} 1}$

$\mathrm{AgS}{ }^{t} \mathrm{Bu}(0.02 \mathrm{~g}, 0.1 \mathrm{mmol})$ and $\mathrm{CF}_{3} \mathrm{COOAg}(0.022 \mathrm{~g}, 0.10 \mathrm{mmol})$ were dissolved in $3 \mathrm{~mL}$ of DMAc solvent under stirring for $5 \mathrm{~min}$. Then, $1 \mathrm{~mL}$ of DMAc solution containing 4-dimethylaminopyridine $(12 \mathrm{mg}, 0.1 \mathrm{mmol})$ was added dropwise. After the mixture was allowed to stand for several days, and colorless needle-like crystals were deposited.

\section{Synthesis of Ag-TPP}
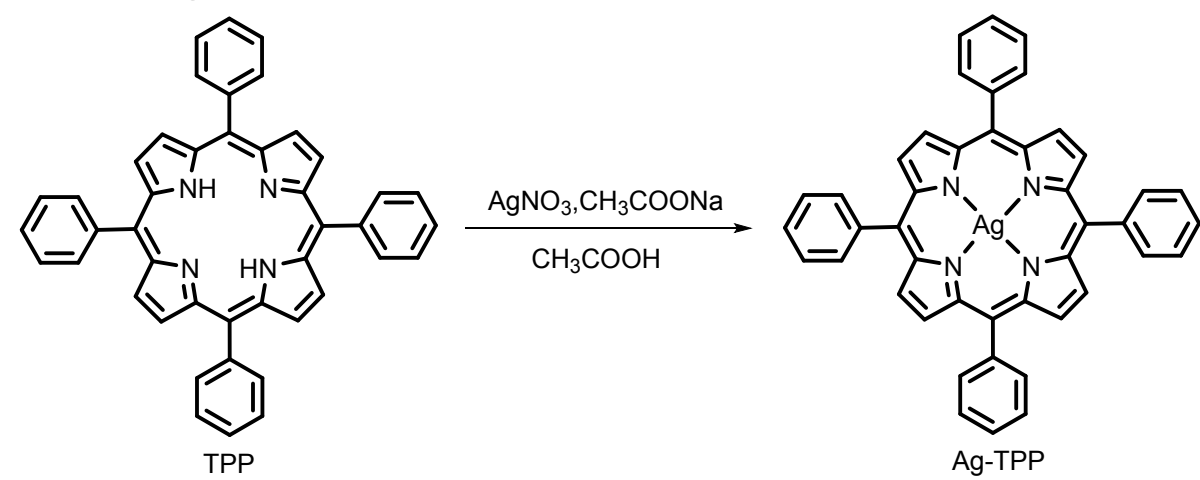

Ag-TPP samples were synthesized according to a previous report. ${ }^{\mathrm{S} 2}$

Under an argon atmosphere, 5,10,15,20-tetraphenylporphyrin (1 mmol), $\mathrm{AgNO}_{3}$ $(10 \mathrm{mmol})$, and $\mathrm{CH}_{3} \mathrm{COONa}(10 \mathrm{mmol})$ were dissolved in acetic acid $(150 \mathrm{~mL})$, and 
then the mixture was refluxed for $3 \mathrm{~h}$. After the mixture cooled to room temperature, dichloromethane was used to extract the product. The mixture was washed with water and a saturated $\mathrm{Na}_{2} \mathrm{CO}_{3}$ solution. Dichloromethane solvent was removed by vacuum distillation. The solid was dissolved in trichloromethane and filtered through a neutral alumina using dichloromethane/n-hexane as eluent to afford the target product as a purple colored solid. UV-vis: $\lambda_{\max }=422 \mathrm{~nm}$ (Soret band), $540 \mathrm{~nm}$ (Q-band). 


\section{Part S3. Characterization of $\operatorname{Ag}_{12}$ TPyP}

\section{Crystal data and structure refinement for $\mathbf{A g}_{12}$ TPyP}

Data collection and reduction were performed using the CrysAlisPro program. The structure was solved by intrinsic phasing methods $\left(\right.$ SHELXT-2015) ${ }^{\mathrm{S} 3}$ and refined by full-matrix least squares on $\mathrm{F}^{2}$ using $O L E X 2^{\mathrm{S} 4}$, which utilizes the SHELXL-2015 module ${ }^{\mathrm{S} 5}$. All solvents were masked.

Table S1. Crystal data and structure refinements

\begin{tabular}{ll}
\hline & $\mathbf{A g}_{12} \mathbf{T P y P}$ \\
\hline CCDC number & 1917151 \\
Empirical formula & $\mathrm{C}_{76} \mathrm{H}_{80} \mathrm{Ag}_{12} \mathrm{~F}_{18} \mathrm{~N}_{8} \mathrm{O}_{12} \mathrm{~S}_{6}$ \\
Formula weight & 3126.28 \\
Temperature / $\mathrm{K}$ & $100.01(10)$ \\
Crystal system & triclinic \\
Space group & $\mathrm{P}-1$ \\
$a / \AA$ & $14.77100(10)$ \\
$b / \AA$ & $15.4918(2)$ \\
$c / \AA$ & $15.6410(2)$ \\
$\alpha /{ }^{\circ}$ & $61.4520(10)$ \\
$\beta / \circ$ & $68.2290(10)$ \\
$\gamma /{ }^{\circ}$ & $67.3880(10)$ \\
$V$ Volume / $\AA^{3}$ & $2823.93(7)$ \\
$Z$ & 1 \\
$\rho_{\text {calc }} \mathrm{g} /$ cm \\
$\mu /$ mm
\end{tabular}


2. Crystal Structure and Characterization of $\operatorname{Ag}_{12} \mathrm{TPyP}$

(a)

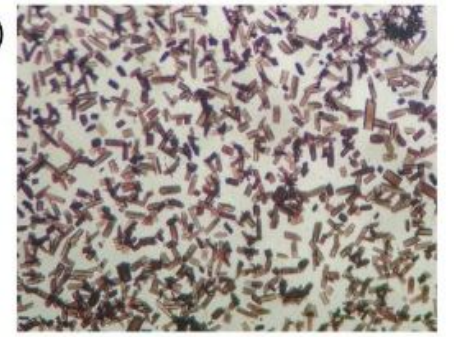

(b)

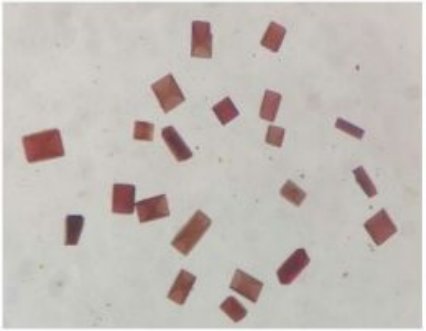

Figure S1. Optical microscope images of single crystals.

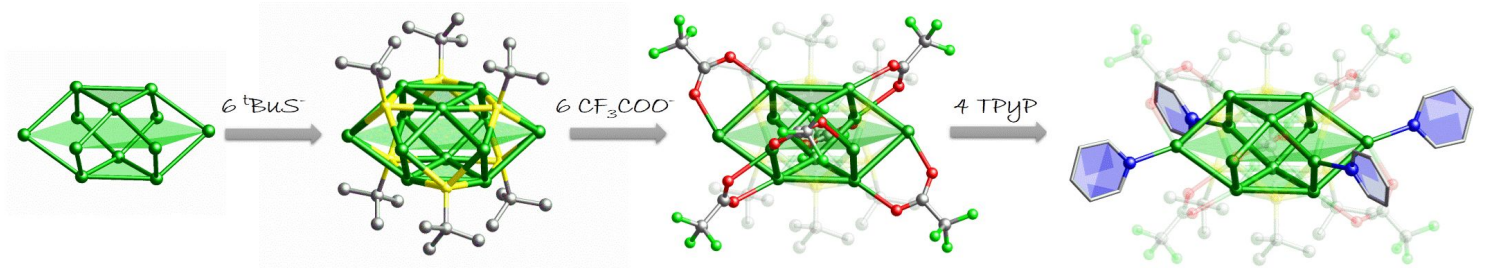

Figure S2. The structure and coordination mode of $\mathbf{A g}_{12} \mathbf{T P y} \mathbf{P}$.

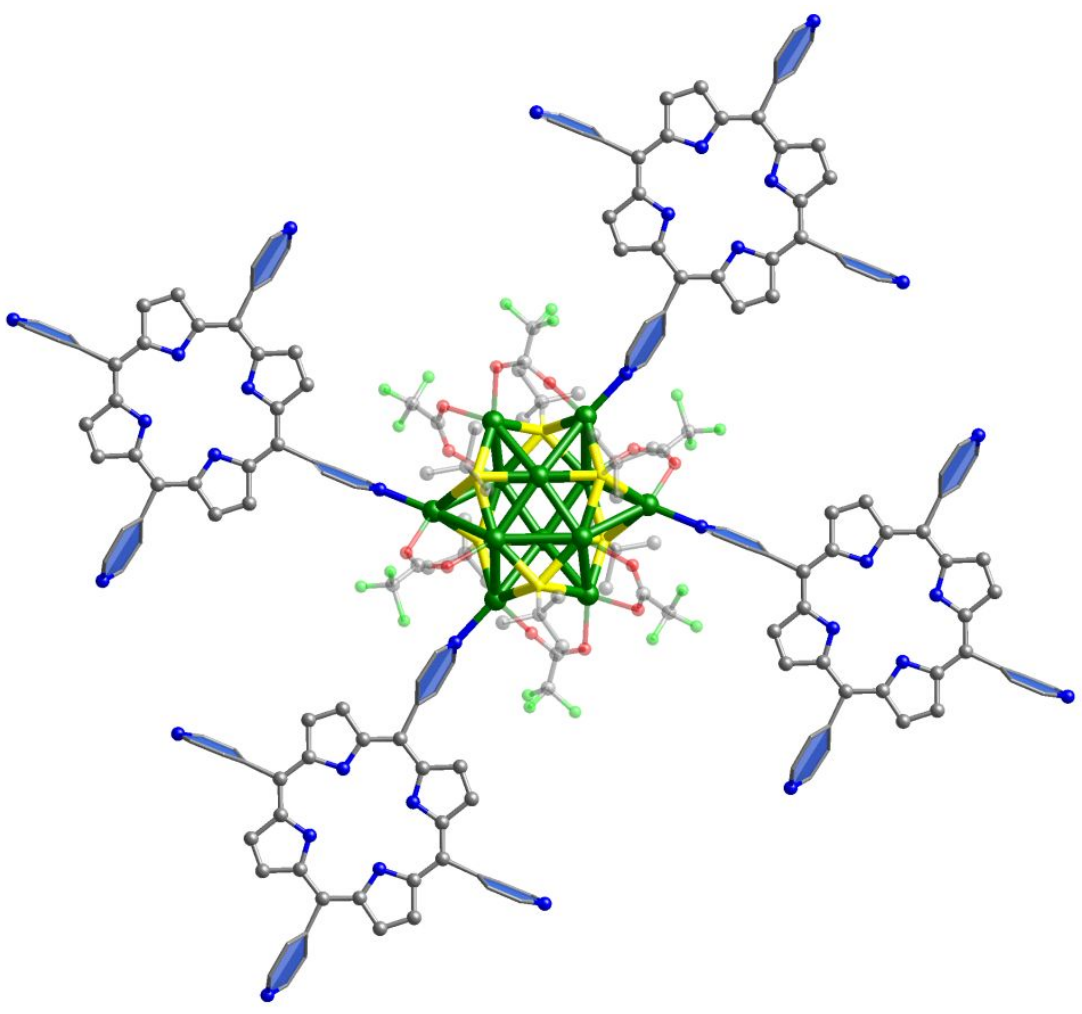

Figure S3. Crystal Structure of $\mathbf{A g}_{12} \mathbf{T P y P}$. 

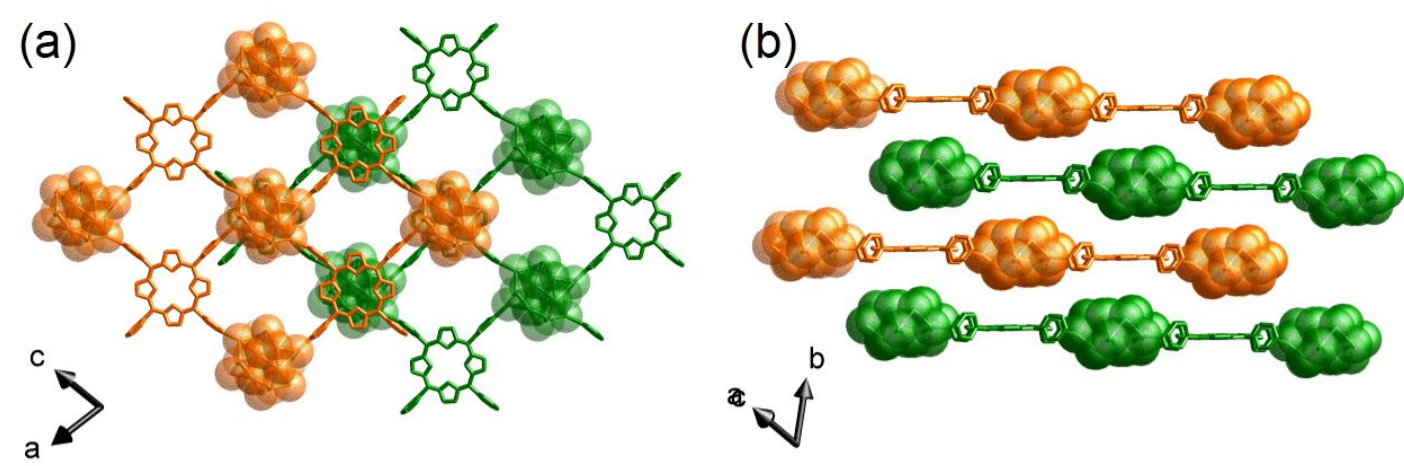

Figure S4. Stacking of the 2D network structure of $\mathbf{A g}_{12} \mathbf{T P y P}$.

\section{Powder X-ray diffraction of $\operatorname{Ag}_{12}$ TPyP}

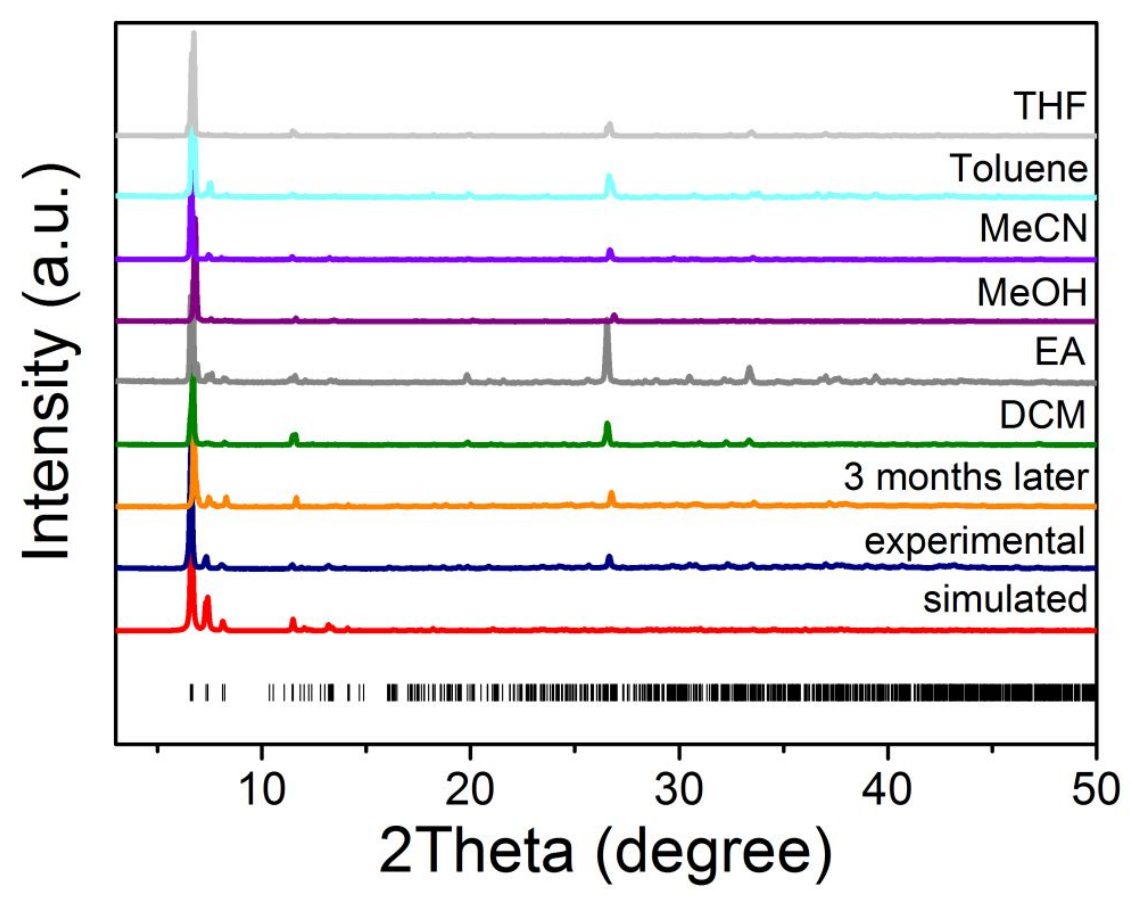

Figure S5. PXRD patterns of $\mathbf{A g}_{12} \mathbf{T P y P}$ after exposure to air over 3 months or soaking in various organic solvents for $36 \mathrm{~h}$.

\section{Gas Adsorption Analysis of $\mathrm{Ag}_{12} \mathrm{TPyP}$}

Before carrying out gas adsorption measurement, $\mathbf{A g}_{\mathbf{1 2}}$ TPyP samples were washed with $\mathrm{MeOH}$ and $\mathrm{MeCN}$, and then soaked in ether for 2-3 days. After the ether removal by decantation, the samples were dried under high vacuum at $40{ }^{\circ} \mathrm{C}$ for $2 \mathrm{~h}$ to remove the solvent molecules before measurements. 


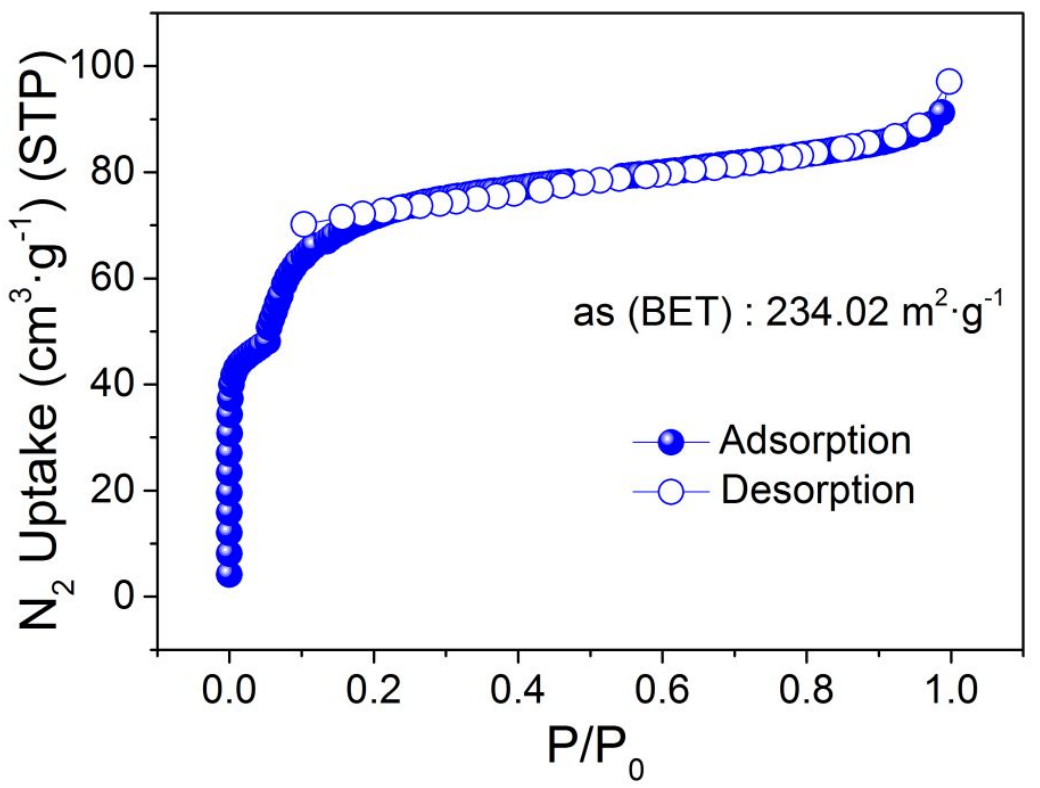

Figure S6. $\mathrm{N}_{2}$ sorption isotherms of $\mathbf{A g}_{12} \mathbf{T P y P}$ at $77 \mathrm{~K}$.

The pore size distribution profiles based on the nonlocal density function theory (NLDFT) method revealed a value approximately $\quad 0.39-0.61 \mathrm{~nm}$.

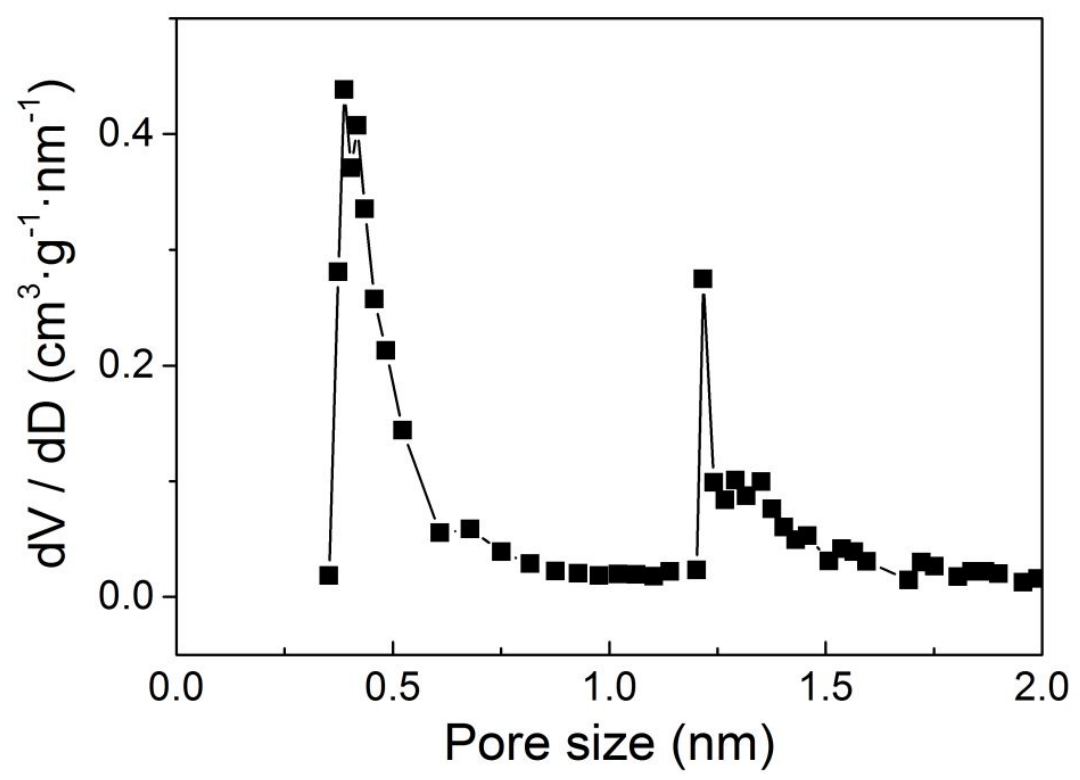

Figure S7. Pore size distribution profile based on nonlocal density function theory (NLDFT) of $\operatorname{Ag}_{12}$ TPyP. 


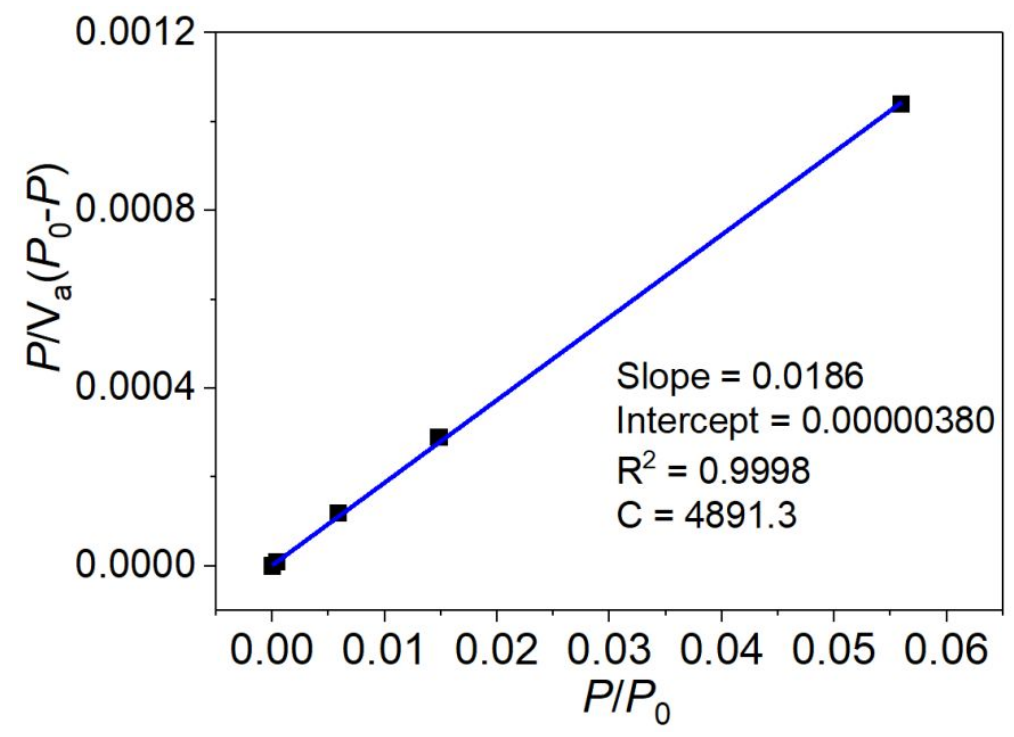

Figure S8. Selected BET Plots of $\mathbf{A g}_{12} \mathbf{T P y P}$ for BET surface area calculation and constant $\mathrm{C}$ based on nitrogen adsorption isotherm at $77 \mathrm{~K}$.

\section{UV-Vis spectroscopy of $\mathrm{Ag}_{12} \mathrm{TPy} P$}

The optical energy gap (Eg) can be estimated by linear extrapolation of the absorption edge and the equation $\mathrm{Eg}=1240 / \lambda \mathrm{g}$, in which $\lambda \mathrm{g}$ is the wavelength of the absorption edge.

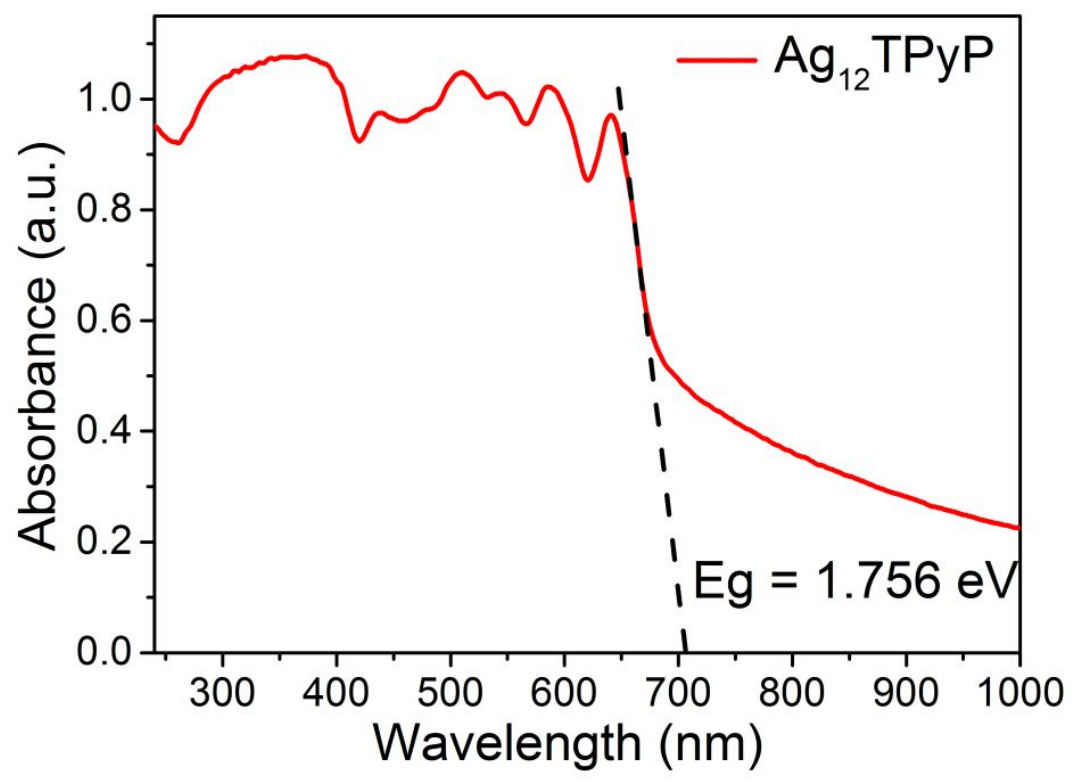

Figure S9. Solid state diffuse reflectance spectrum and determined optical energy gaps of $\operatorname{Ag}_{12}$ TPyP. 
6. TG curve of $\operatorname{Ag}_{12} \mathrm{TPyP}$

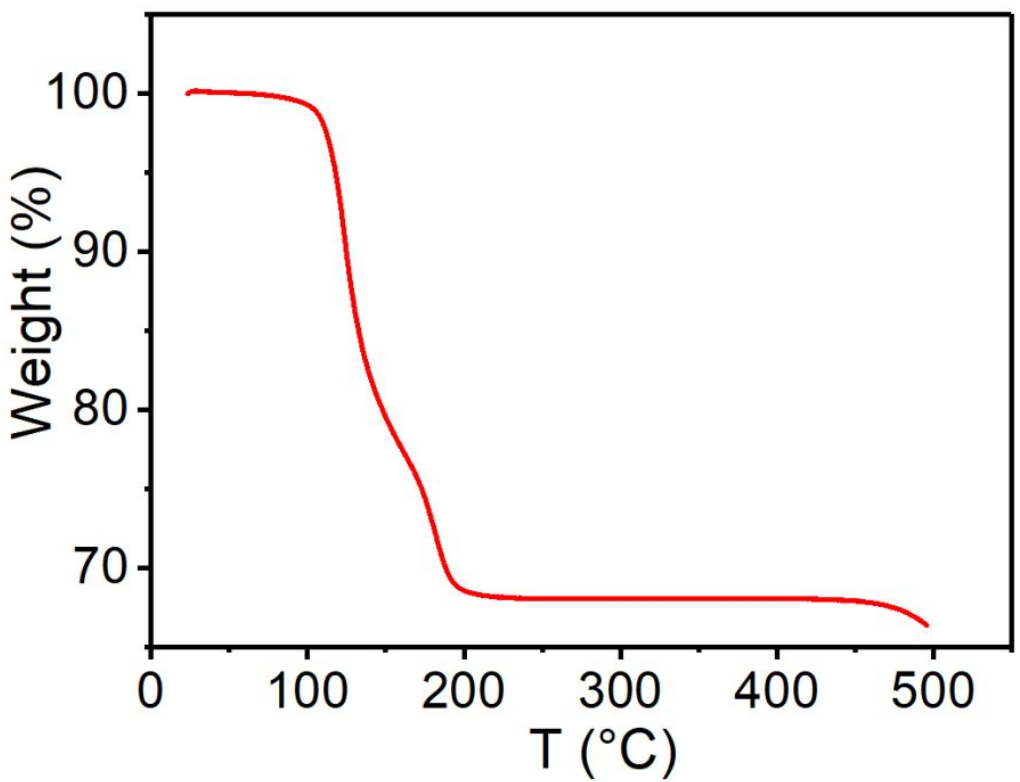

Figure S10. The TG curve of $\mathbf{A g}_{12} \mathbf{T P y P}$ 


\section{Part S4. Characterization of $\operatorname{Ag}_{12} \mathrm{bpy}-2$}

\section{Crystal Structure of $\mathrm{Ag}_{12} \mathrm{bpy}-2$}

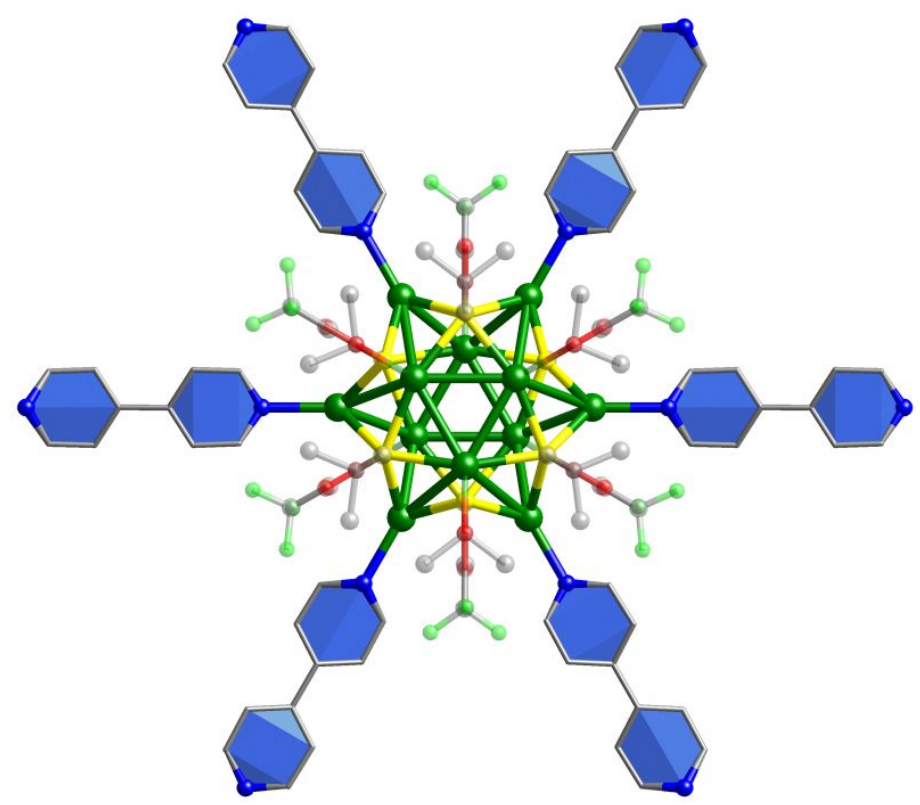

Figure S11. Crystal structure of $\mathbf{A g}_{12} \mathbf{b p y}-\mathbf{2}$.

a)

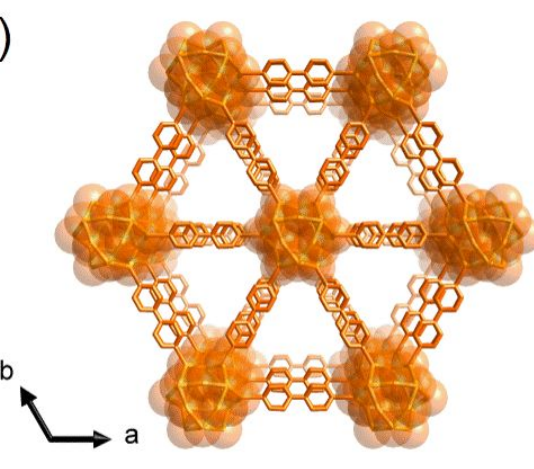

b)

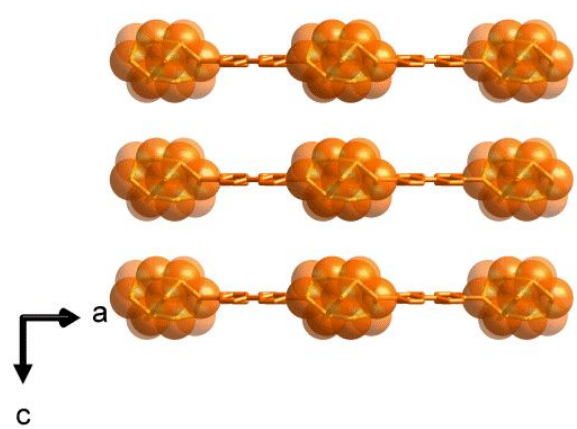

Figure S12. Stacking of the 2D network structure of $\mathbf{A g}_{12} \mathbf{b p y} \mathbf{b}$ viewed along the c-axis (a) and baxis (b) 
2. Gas Adsorption Analysis of $\mathbf{A g}_{12} \mathrm{bpy}-2$

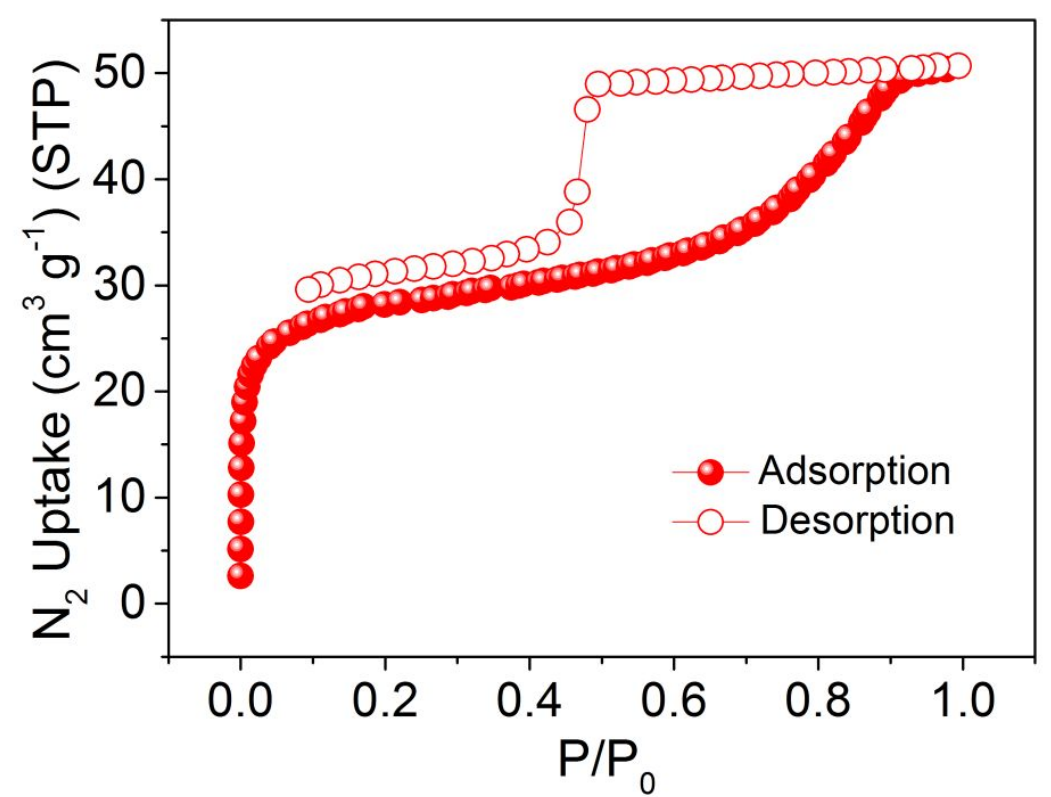

Figure S13. $\mathrm{N}_{2}$ adsorption-desorption isotherm of $\mathbf{A g}_{12} \mathbf{b p y}-\mathbf{2}$ at $77 \mathrm{~K}$.

3. UV-Vis spectroscopy of $\operatorname{Ag}_{12} \mathrm{bpy}-2$

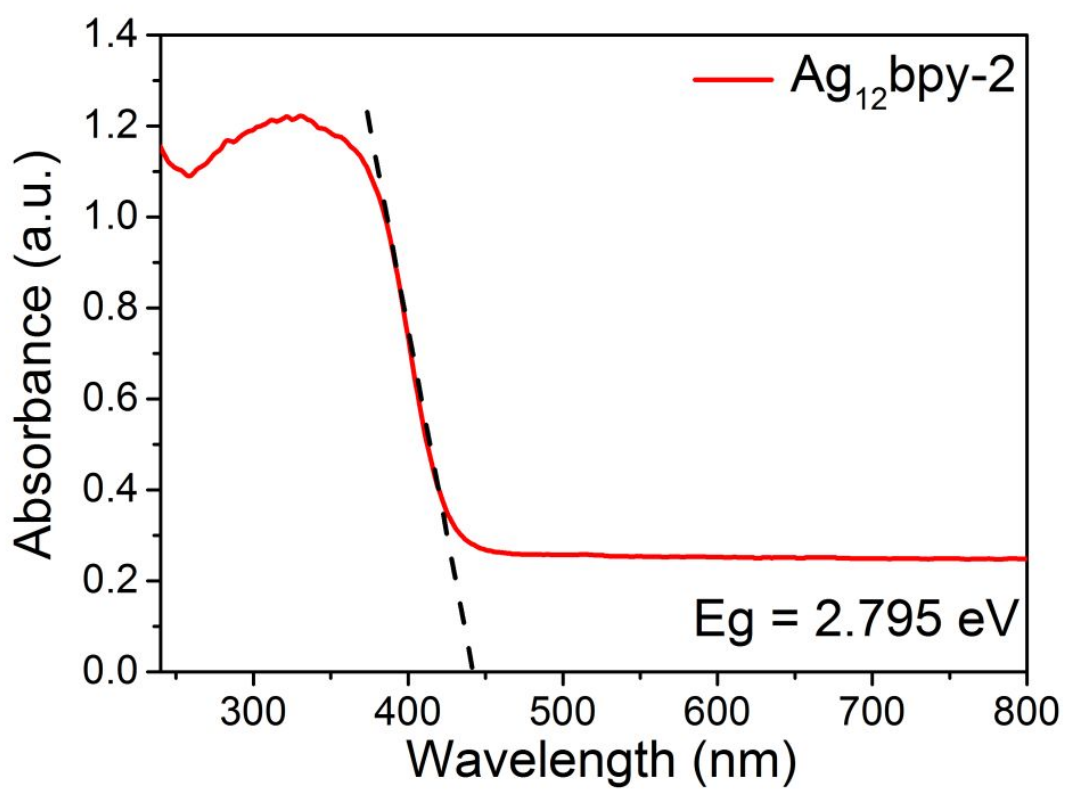

Figure S14. Solid state diffuse reflectance spectrum and determined optical energy gaps of $\mathrm{Ag}_{12}$ bpy-2. 


\section{Part S5. Detection of ${ }^{1} \mathrm{O}_{2}$ Generation}

\section{4-охо-TMP}

2,2,6,6-Tetramethyl-4-piperidone (4-oxo-TMP) was used as a probe to spin trap ${ }^{1} \mathrm{O}_{2}$ and afford stable 4-oxo-2,2,6,6-tetramethyl-1-piperidinyloxy (4-oxo-TEMPO), which can be detected via electron paramagnetic resonance (EPR) spectroscopy.

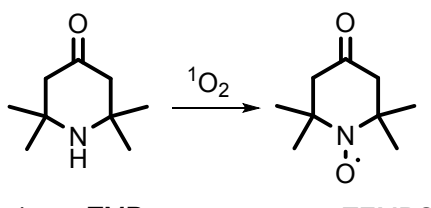

4-oxo-TMP 4-oxo-TEMPO

\section{DMA}

9,10-Dimethylanthracene (DMA) is a fluorescent probe that can be used to detect singlet oxygen production in EtOH. Typically, $2 \mathrm{mg}$ of DMA was dissolved in $4 \mathrm{~mL}$ of EtOH with $0.48 \mu \mathrm{mol}$ TPyP, Ag-TPyP, $\mathbf{A g}_{12} \mathbf{T P y P}$ or $\mathbf{A g}_{12} \mathbf{b p y}-2$ under white LED light irradiation. Our experimental results were monitored by the fluorescence emission peaks decay at 430 and $451 \mathrm{~nm}(\mathrm{ex}: 300 \mathrm{~nm})$.
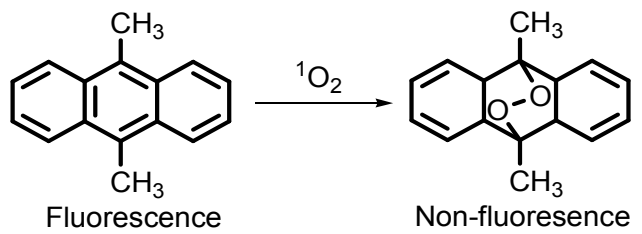

The luminescence spectra of $\mathbf{A g}_{12} \mathbf{T P y P}$ in the 400-530 $\mathrm{nm}$ region indicated that $\mathbf{A g}_{12}$ TPyP showed a negligible effect on the DMA degradation experiment

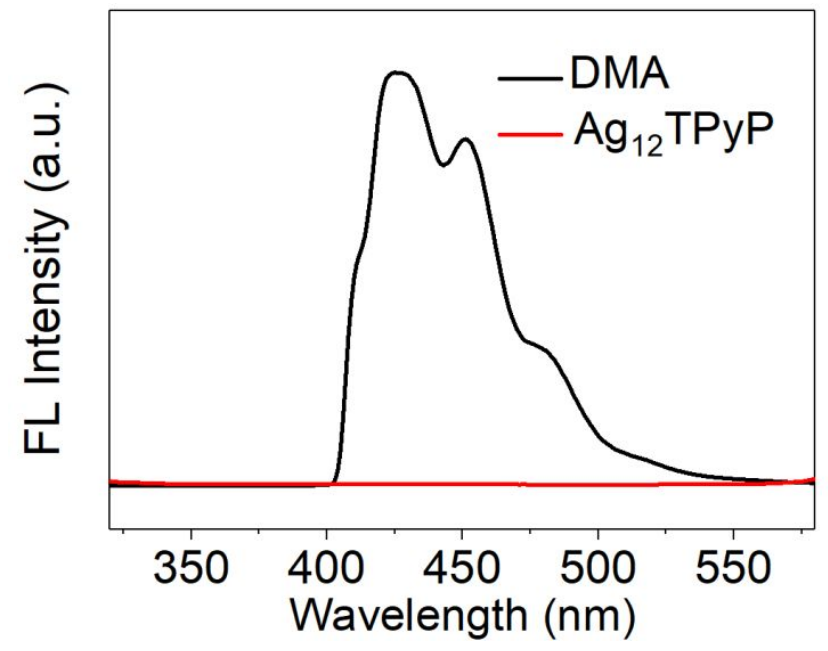

Figure S15. The luminescence spectra of DMA and $\mathbf{A g}_{12} \mathbf{T P y P}$ excited at $300 \mathrm{~nm}$. 
The degradation rate of $\mathrm{Ag}_{12}$ bpy-2 is much slower compared with $\mathrm{Ag}_{12} \mathrm{TPyP}$, this result is attributable to the narrow absorption region and corresponding larger band gap of $\mathrm{Ag}_{12}$ bpy-2 (Figure S14).

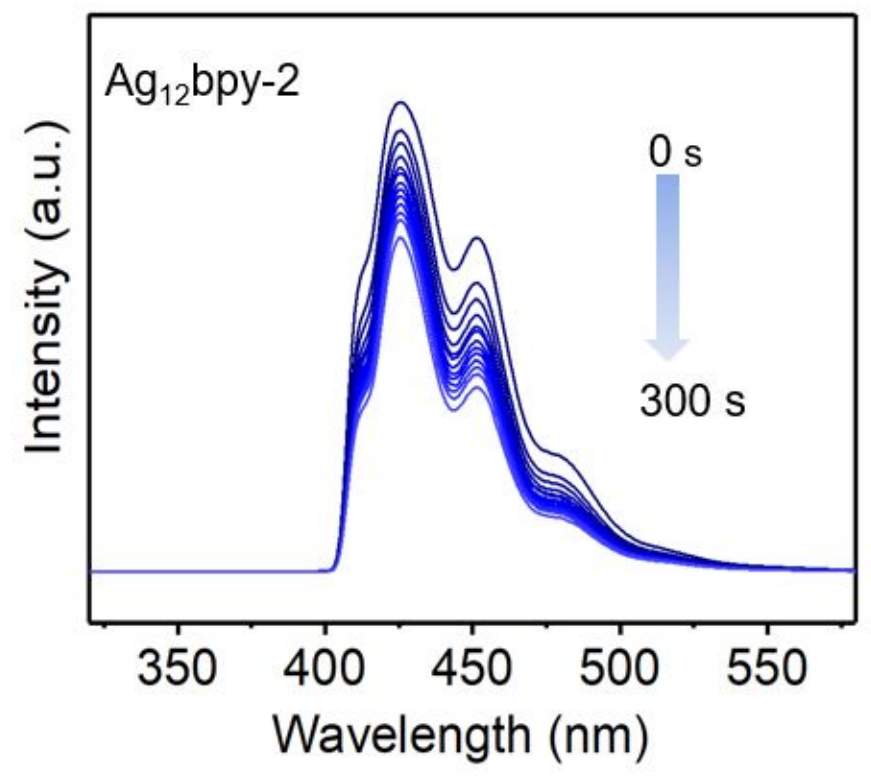

Figure S16. Emission spectrum of DMA in the presence of $\mathbf{A g}_{12} \mathbf{b p y} \mathbf{b}$.

To exclude the effect of bpy on ${ }^{1} \mathrm{O}_{2}$ generation, we conducted the DMA degradation experiment with isolated bpy. The results showed that bpy was unable to degrade DMA, demonstrating that the ability of $\mathrm{Ag}_{12} \mathrm{bpy}-2$ to generate ${ }^{1} \mathrm{O}_{2}$ is originating from the silver cluster.

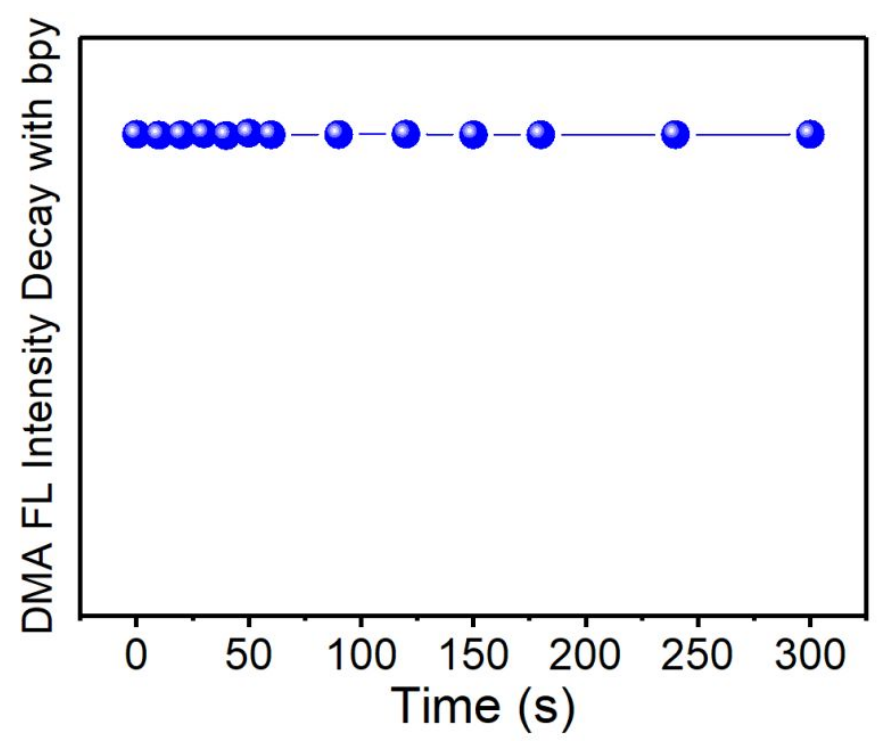

Figure S17. The degradation of DMA using bpy as monitored by the fluorescence emission spectra. 


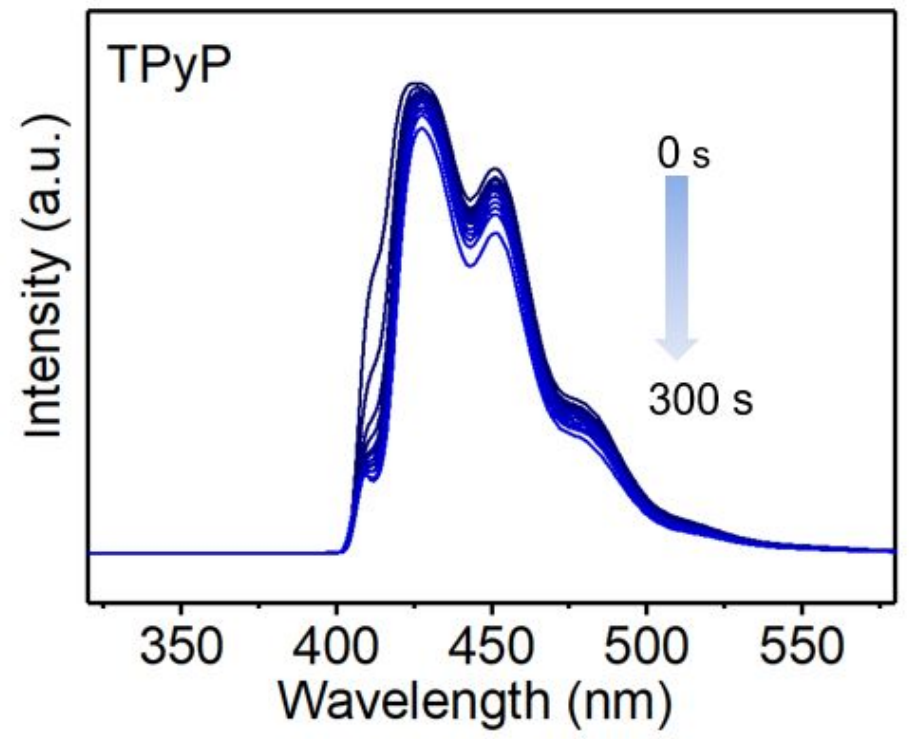

Figure S18. Emission spectrum of DMA in the presence of TPyP.

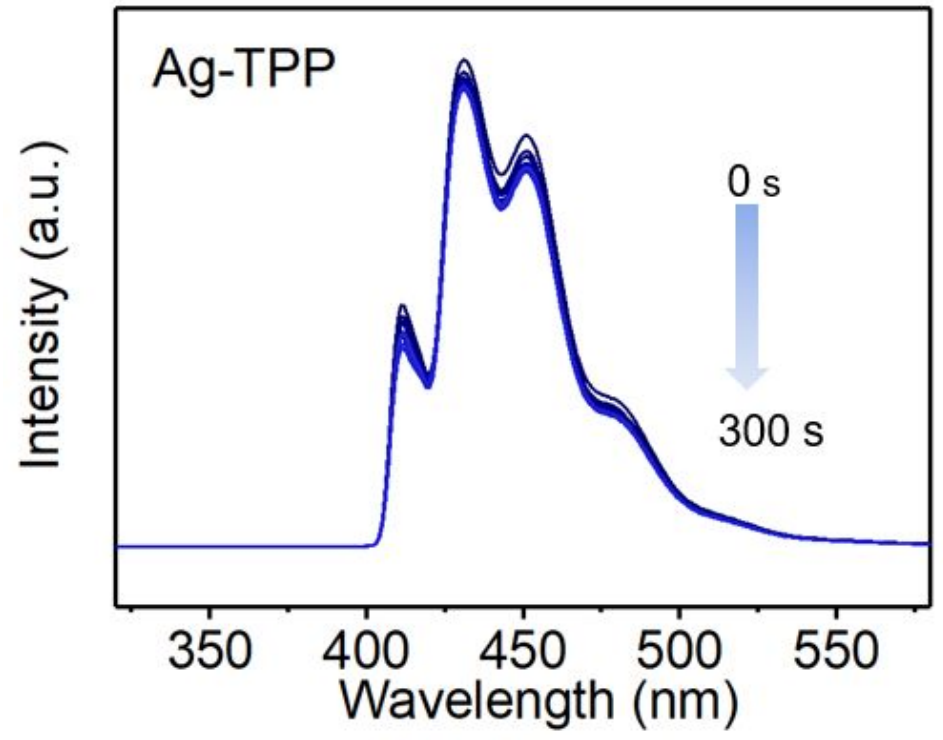

Figure S19. Emission spectrum of DMA in the presence of Ag-TPP. 


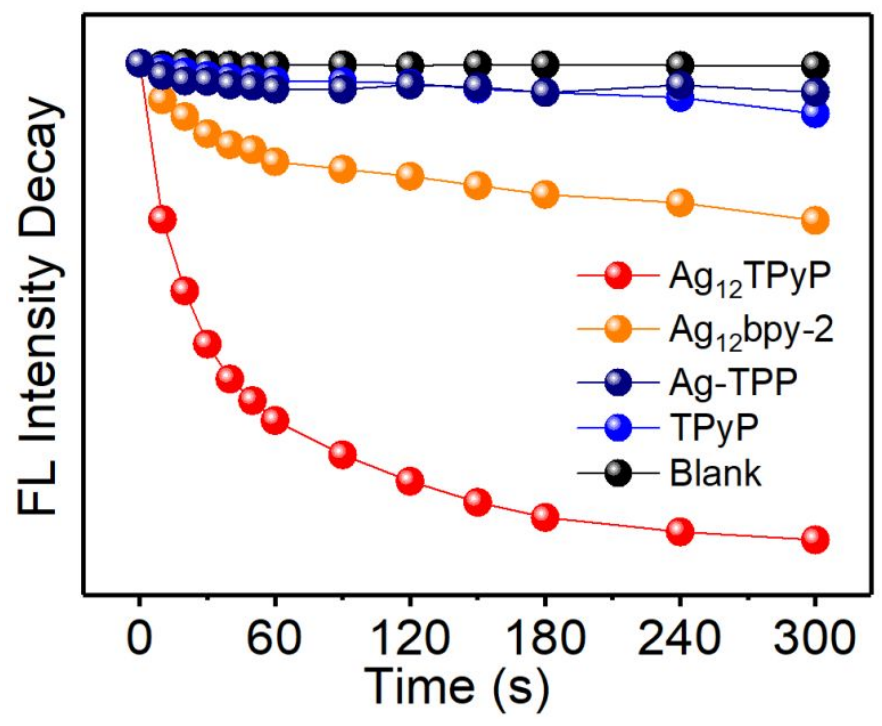

Figure S20. The degradation of DMA using $\mathbf{A g}_{12} \mathbf{T P y P}, \mathbf{A g}_{12} \mathbf{b p y - 2}, \mathbf{A g}-\mathbf{T P P}$ and $\mathbf{T P y P}$ as monitored by the emission decay at $430 \mathrm{~nm}$. 


\section{Part S6. Capability of $\operatorname{Ag}_{12}$ TPyP to capture CEES}

\section{XPS}

Preparation of $\mathbf{A g}_{12}$ TPyP-CEES: $\mathbf{A g}_{12}$ TPyP crystals were dispersed in $0.05 \mathrm{M}$ $\mathrm{CEES}$ in $\mathrm{EtOH}$ for $10 \mathrm{~min}$. Then, the remaining powder was washed three times with ethanol and dried.

a)

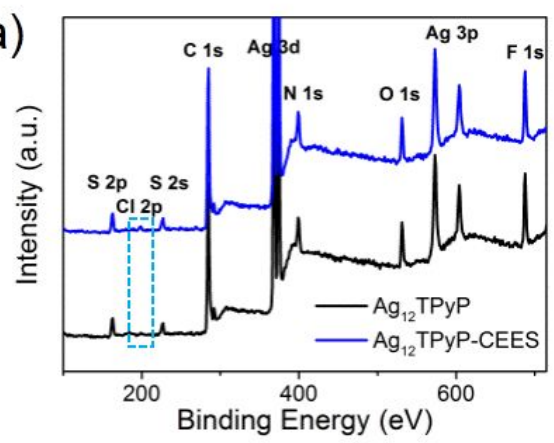

c)

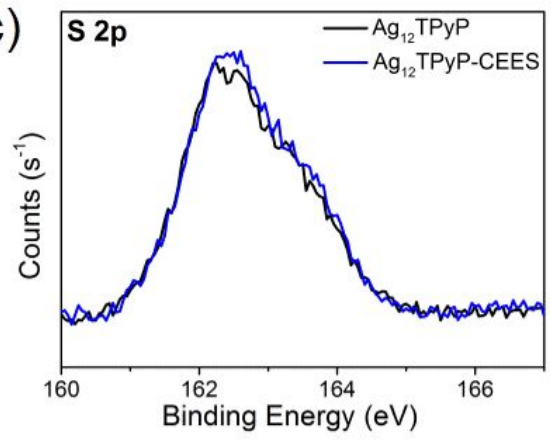

b)

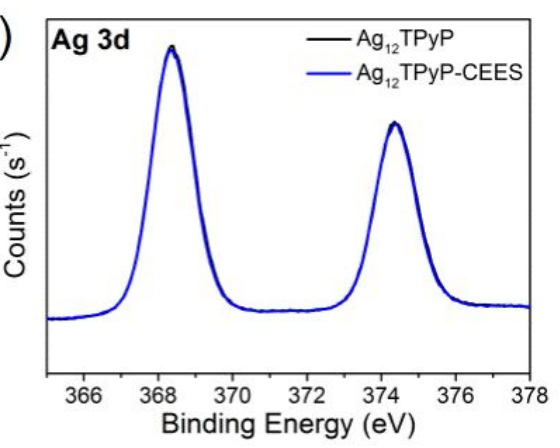

d)

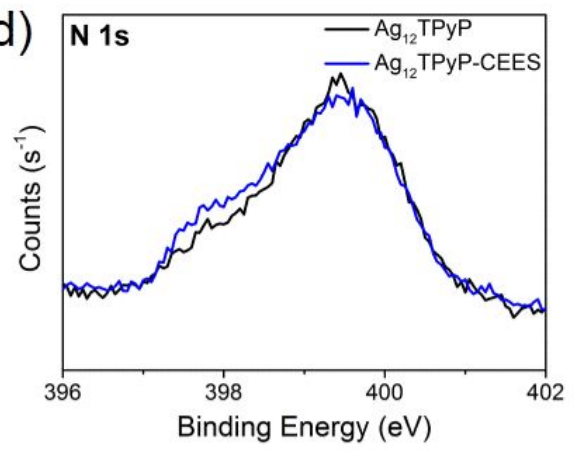

Figure S21. (a) Full X-Ray photoelectron spectroscopy (XPS) spectra of $\mathbf{A g}_{12} \mathbf{T P y P}$ and $\mathbf{A g}_{12} \mathbf{T P y} \mathbf{P}$ CEES; (b, c, d) Ag 3d, S 2p and N 1s high-resolution XPS spectra of $\mathbf{A g}_{12} \mathbf{T P y P}$ and $\mathbf{A g}_{12} \mathbf{T P y P}$ CEES. 


\section{Mapping}

$\operatorname{Ag}_{12} \mathbf{T P y} P$ crystals were dispersed in 0.1 M CEES in EtOH for $10 \mathrm{~min}$. Then, it was dripped onto the conducting substrates and dried under ambient conditions for the SEM measurements.

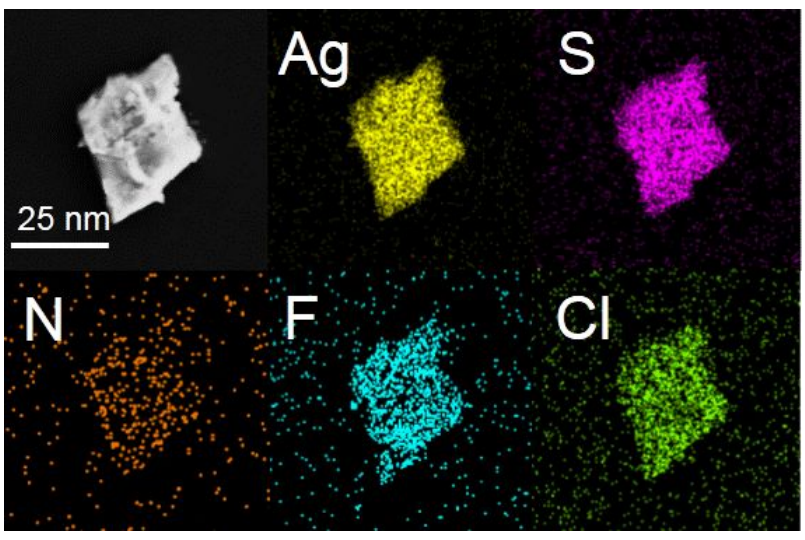

Figure S22. Elemental mapping images of $\mathbf{A g}_{12}$ TPyP-CEES.

\section{PXRD of $\mathrm{Ag}_{12}$ TPyP after CEES vapor sorption experiments}

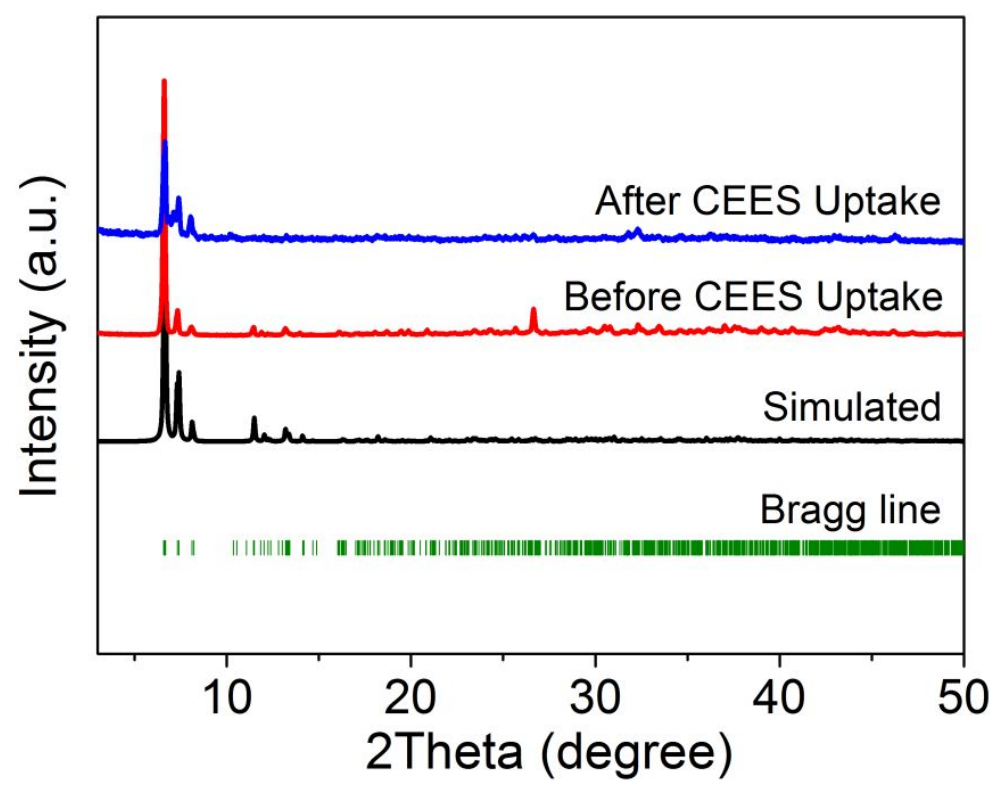

Figure S23. PXRD of $\mathbf{A g}_{12} \mathbf{T P y P}$ after CEES vapor sorption experiments. 
4. CEES uptake isotherms of TPyP and Ag-TPP

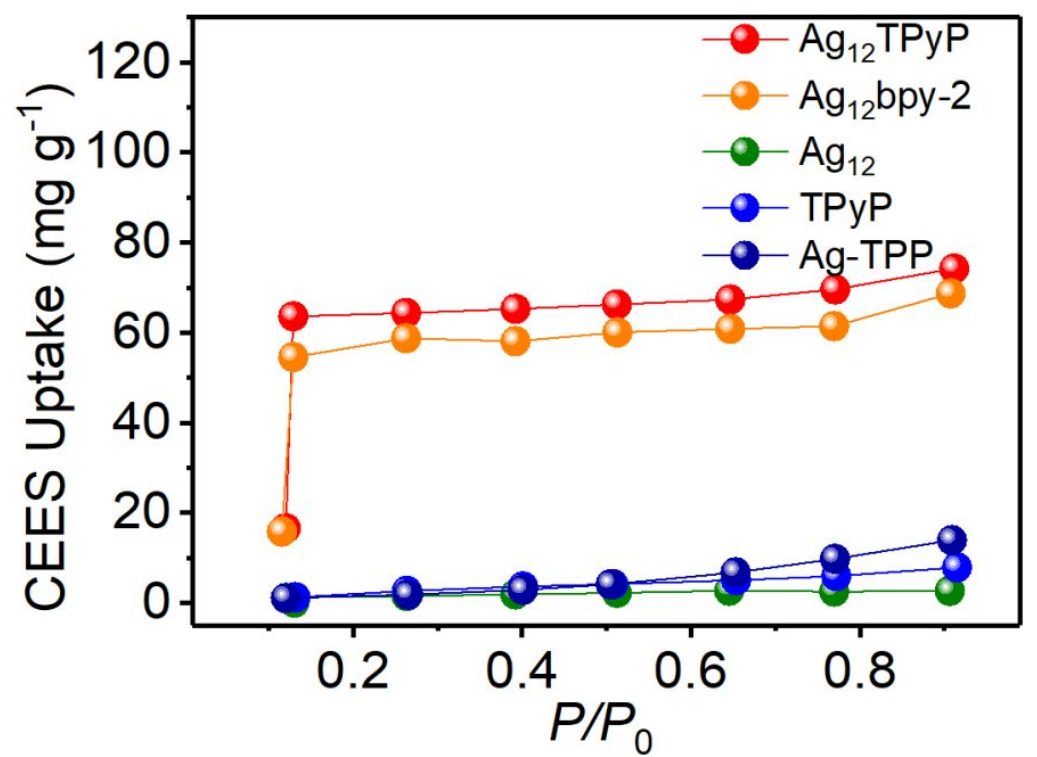

Figure S24. CEES uptake isotherms of $\mathbf{A g}_{12} \mathbf{T P y P}, \mathbf{A g}_{12} \mathbf{b p y - 2}, \mathbf{A g}_{12}$, TPyP and $\mathbf{A g}-\mathbf{T P P}$ at $298 \mathrm{~K}$. 
Part S7. Crystal Structure of $\mathbf{A g}_{12}$

1. Crystal Structures of $\mathbf{A g}_{12}$

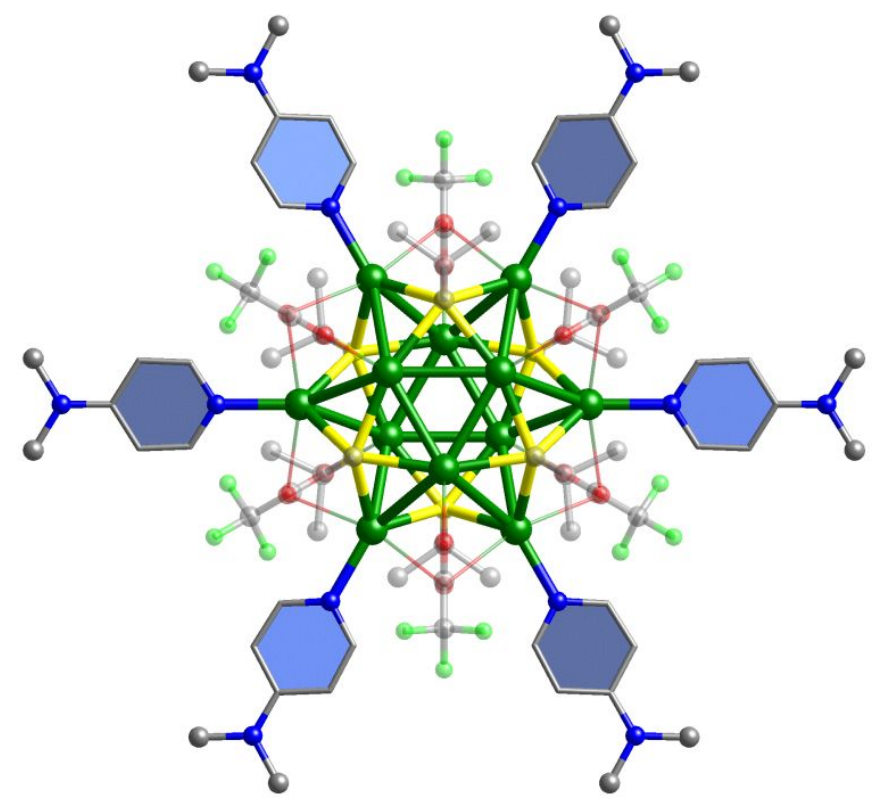

Figure S25. Crystal structure of $\mathbf{A g}_{12}$. 


\section{Part S8. Catalytic Studies}

\section{1. $\mathbf{A g}_{12}$ TPyP Photocatalytic experiment}

$\mathrm{Ag}_{12}$ TPyP (1.5 mg, $0.48 \mu \mathrm{mol} \mathrm{Ag}_{12} / 0.48 \mu \mathrm{mol}$ porphyrin unit) was dispersed in $0.5 \mathrm{~mL}$ of $\mathrm{CD}_{3} \mathrm{OD}$ in a sealed glass reactor. After purging with $\mathrm{O}_{2}$ for $15 \mathrm{~min}, 5.6 \mu \mathrm{L}$ (48 $\mu \mathrm{mol}$ ) of CEES with $0.5 \mathrm{~mL} \mathrm{CD} \mathrm{CD}_{3} \mathrm{OD}$ was added to the glass reactor. After sealing the reactor, it was then exposed to white LED light and monitored by NMR measurement. Measurement under the atmospheric condition was conducted by purging with air instead of oxygen at the beginning of the reaction.

${ }^{1} \mathrm{H}$ NMR and ${ }^{13} \mathrm{C}$ NMR spectra.

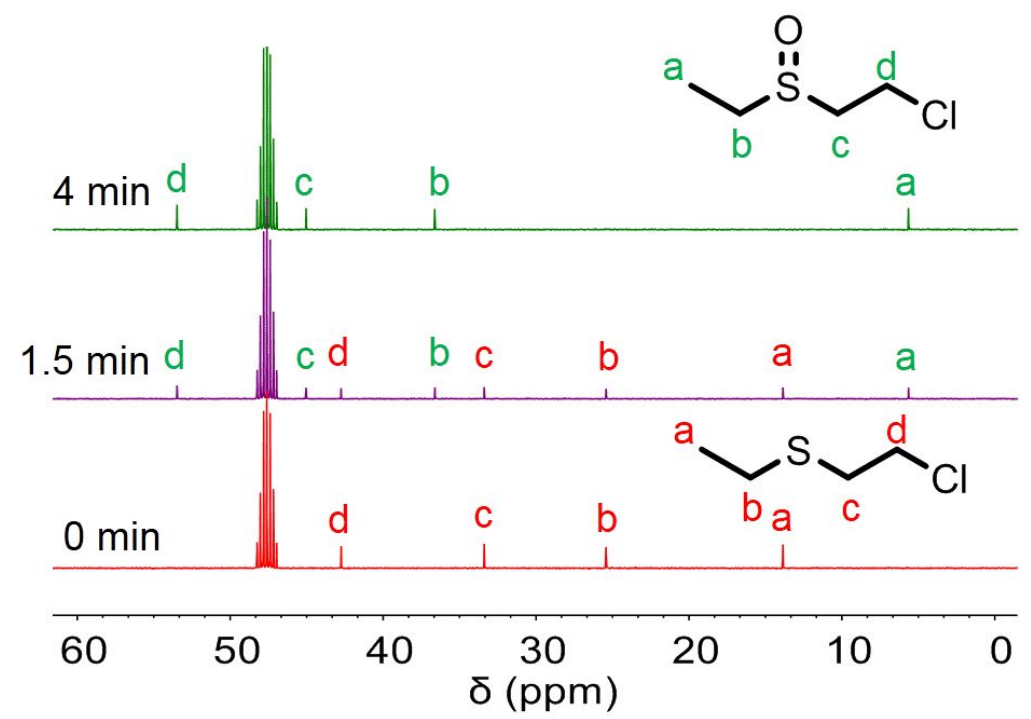

Figure S26. ${ }^{13} \mathrm{C}$ NMR spectra before and after photooxidation reaction of CEES by $\mathbf{A g}_{12} \mathbf{T P y P}$ catalyst.

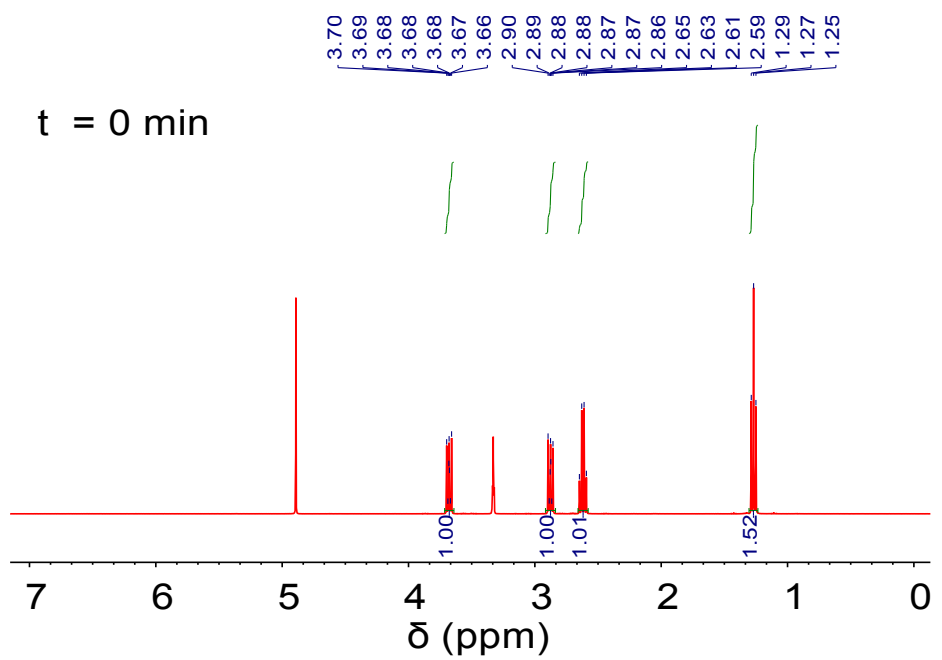

Figure S27. ${ }^{1} \mathrm{H}$ NMR spectrum of CEES oxidation reaction in $\mathrm{CD}_{3} \mathrm{OD}$ in the presence of $1.5 \mathrm{mg}$ $\mathbf{A g}_{12}$ TPyP under white LED $(\mathrm{t}=0 \mathrm{~min})$. 


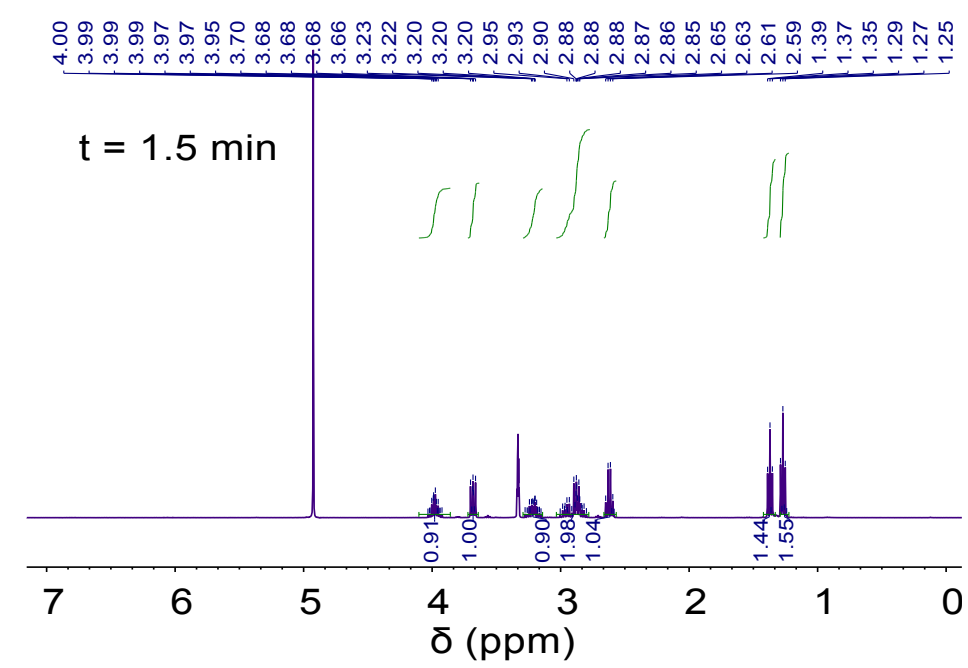

Figure S28. ${ }^{1} \mathrm{H}$ NMR spectrum of CEES oxidation reaction in $\mathrm{CD}_{3} \mathrm{OD}$ in the presence of $1.5 \mathrm{mg}$ $\mathbf{A g}_{12} \mathbf{T P y} \mathbf{P}$ under white LED $(\mathrm{t}=1.5 \mathrm{~min})$.

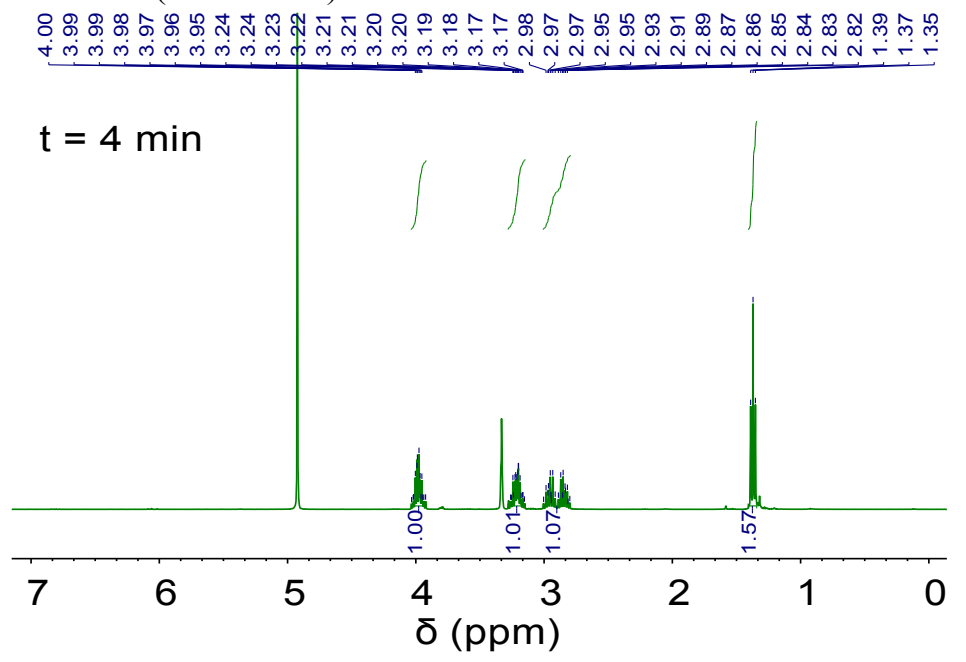

Figure S29. ${ }^{1} \mathrm{H}$ NMR spectrum of CEES oxidation reaction in $\mathrm{CD}_{3} \mathrm{OD}$ in the presence of $1.5 \mathrm{mg}$ $\operatorname{Ag}_{12} \mathbf{T P y} \mathbf{P}$ under white LED $(\mathrm{t}=4 \mathrm{~min})$.

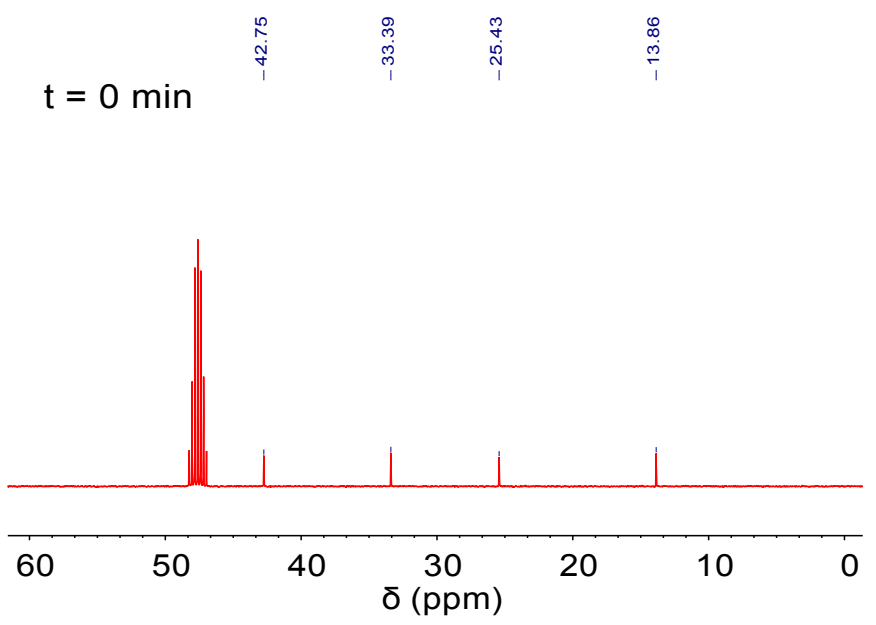

Figure S30. ${ }^{13} \mathrm{C}$ NMR spectrum of CEES oxidation reaction in $\mathrm{CD}_{3} \mathrm{OD}$ in the presence of $1.5 \mathrm{mg}$ $\mathbf{A g}_{12}$ TPyP under white LED $(\mathrm{t}=0 \mathrm{~min})$. 


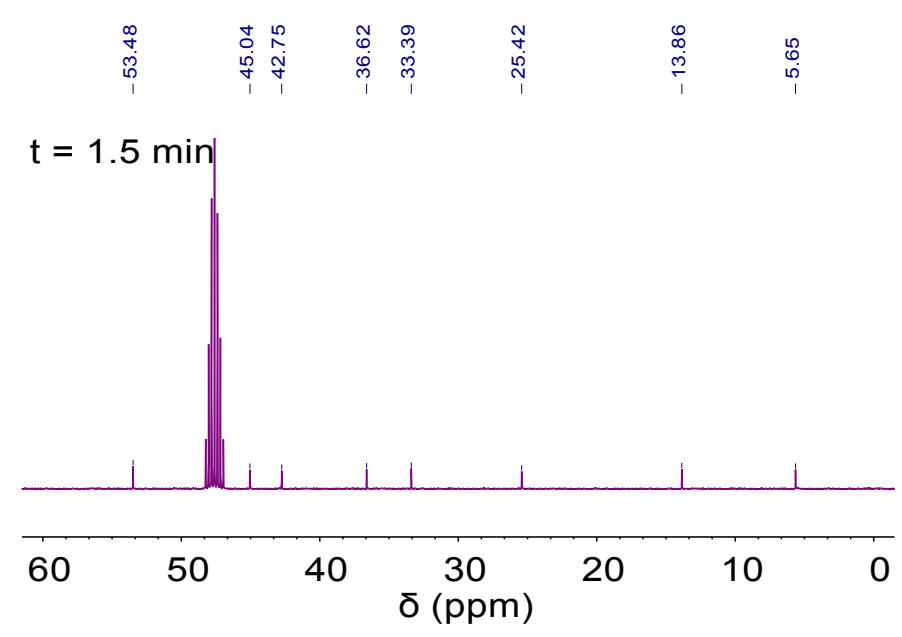

Figure S31. ${ }^{13} \mathrm{C}$ NMR spectrum of CEES oxidation reaction in $\mathrm{CD}_{3} \mathrm{OD}$ in the presence of $1.5 \mathrm{mg}$ $\mathbf{A g}_{12} \mathbf{T P y} \mathbf{P}$ under white LED $(\mathrm{t}=1.5 \mathrm{~min})$.

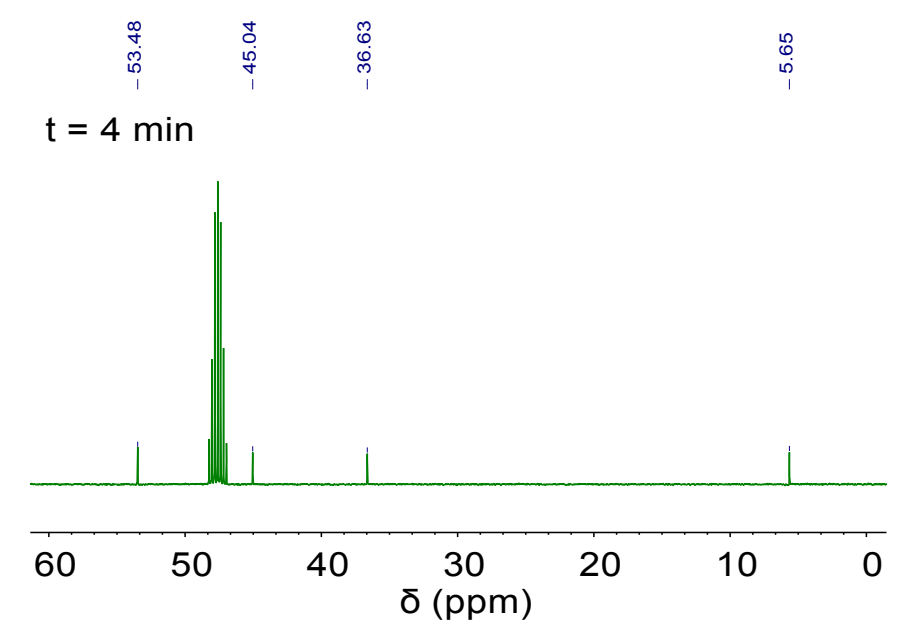

Figure S32. ${ }^{13} \mathrm{C}$ NMR spectrum of CEES oxidation reaction in $\mathrm{CD}_{3} \mathrm{OD}$ in the presence of $1.5 \mathrm{mg}$ $\mathbf{A g}_{12} \mathbf{T P y P}$ under white LED ( $\left.\mathrm{t}=1.5 \mathrm{~min}\right)$.

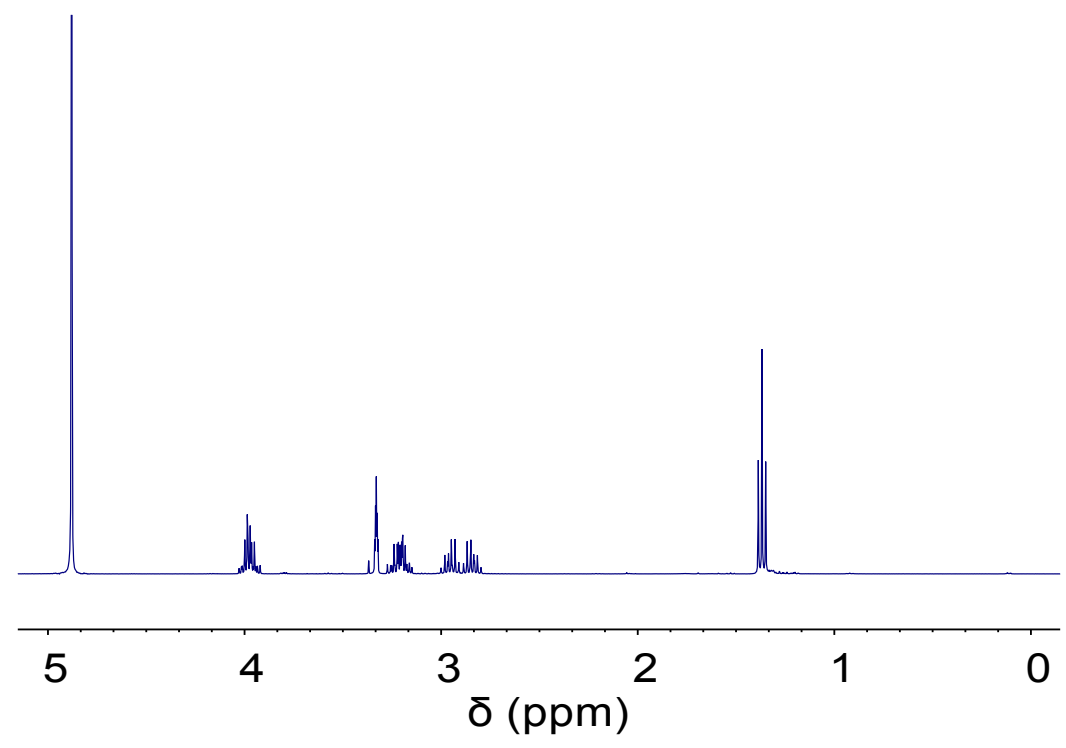

Figure $\mathbf{S 3 3}{ }^{1} \mathrm{H}$ NMR spectrum of CEES oxidation reaction in $\mathrm{CD}_{3} \mathrm{OD}$ over $2 \mathrm{~h}$. 


\section{Catalytic comparison}

$\mathbf{A g}_{12}$ bpy-2, $\mathbf{A g}_{12}$, TPyP and Ag-TPP photocatalytic experiment: Under the same test conditions and maintaining equivalent contents of $\mathrm{Ag}$ cluster $\left(\mathbf{A g}_{\mathbf{1 2}} \mathbf{b p y} \mathbf{\mathbf { b }} \mathbf{2}\right.$ and $\mathbf{A g}_{12}$ ) or porphyrin ligand (pure TPyP ligand and Ag-TPP), the photooxidation CEES experiments were conducted. As shown in Figure S37, the conversion rate of pure $\operatorname{Ag}_{12}$ cluster is almost the same as that of a blank.

It is noted that TPyP and Ag-TPyP cannot be dissolved in $\mathrm{CD}_{3} \mathrm{OD}$. Therefore, we performed the corresponding experiment in $\mathrm{CDCl}_{3}$.

(a)

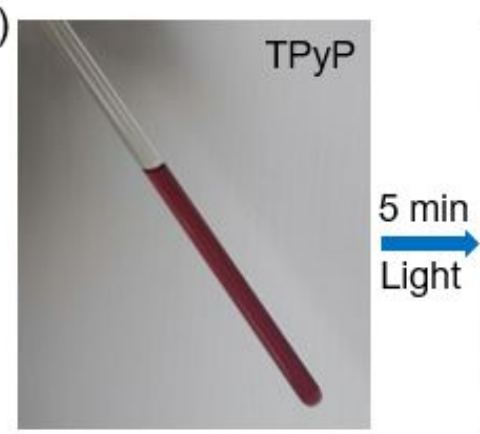

(b)

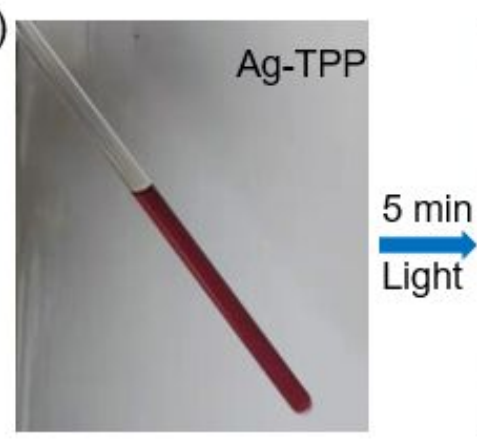

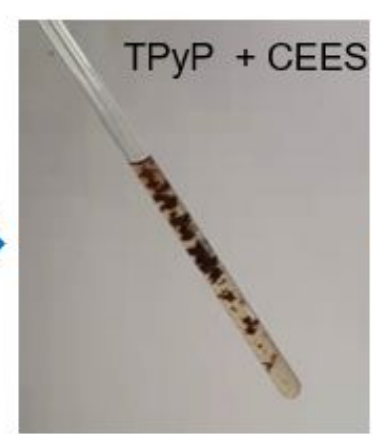
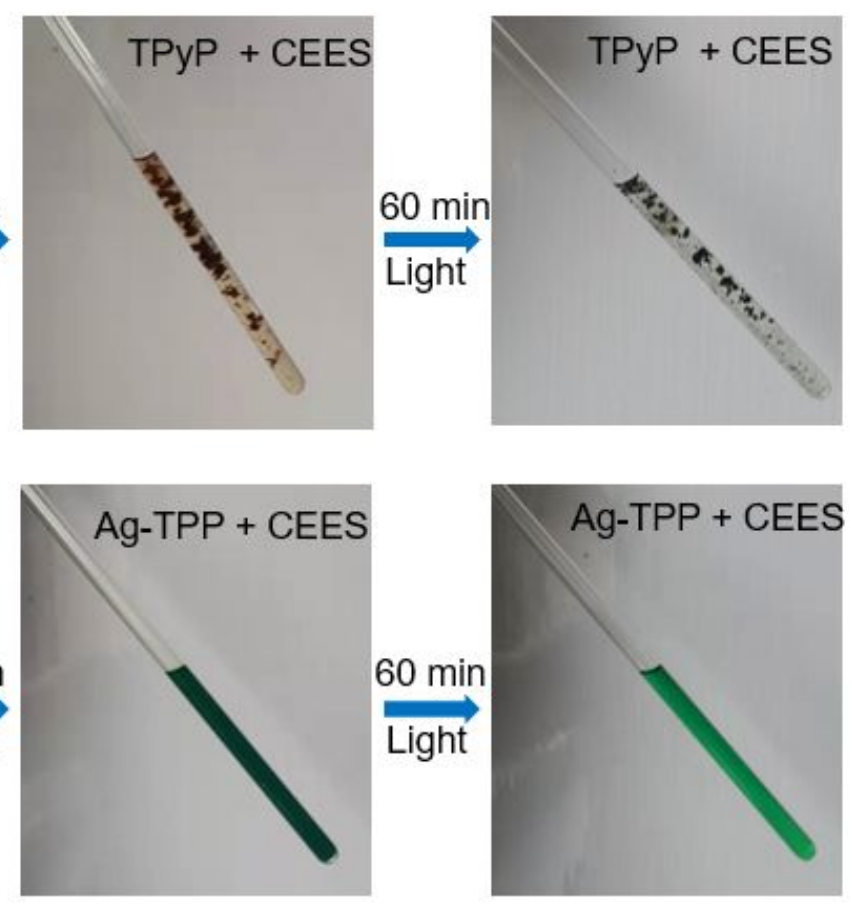

Figure S34. Photos of TPyP (a) and Ag-TPP (b) before and after addition of CEES for 5 and 60 min under light irritation, respectively. 


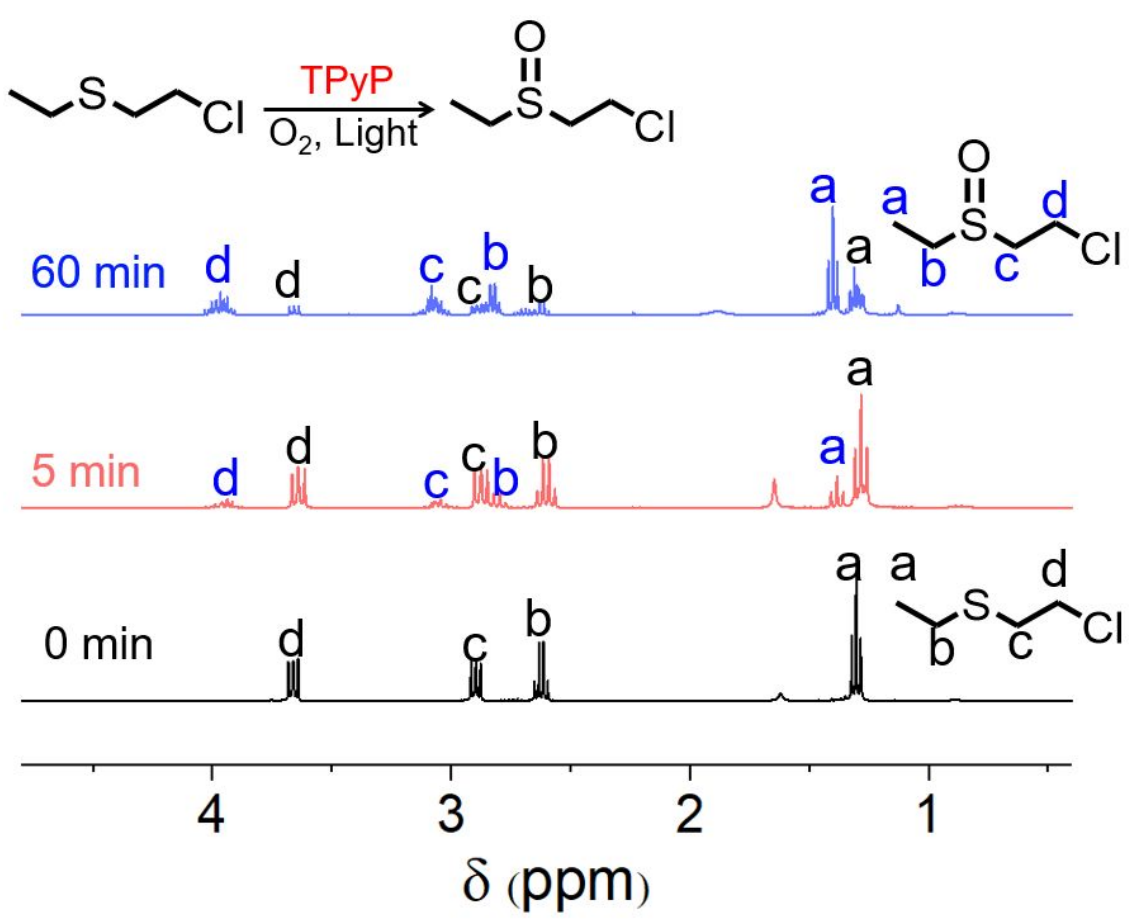

Figure S35. ${ }^{1} \mathrm{H}$ NMR analysis of the photooxidation reaction of CEES by TPyP.

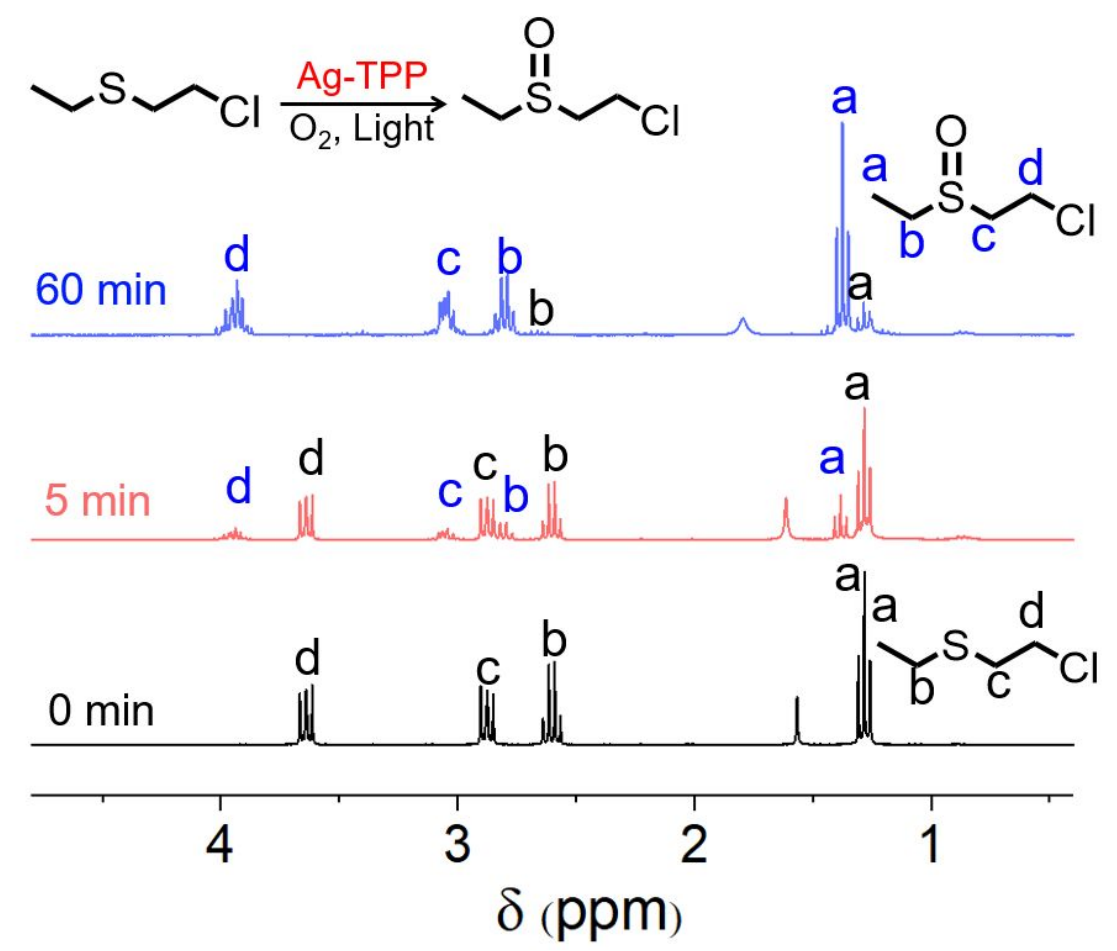

Figure S36. ${ }^{1} \mathrm{H}$ NMR analysis of the photooxidation reaction of CEES by Ag-TPP. 


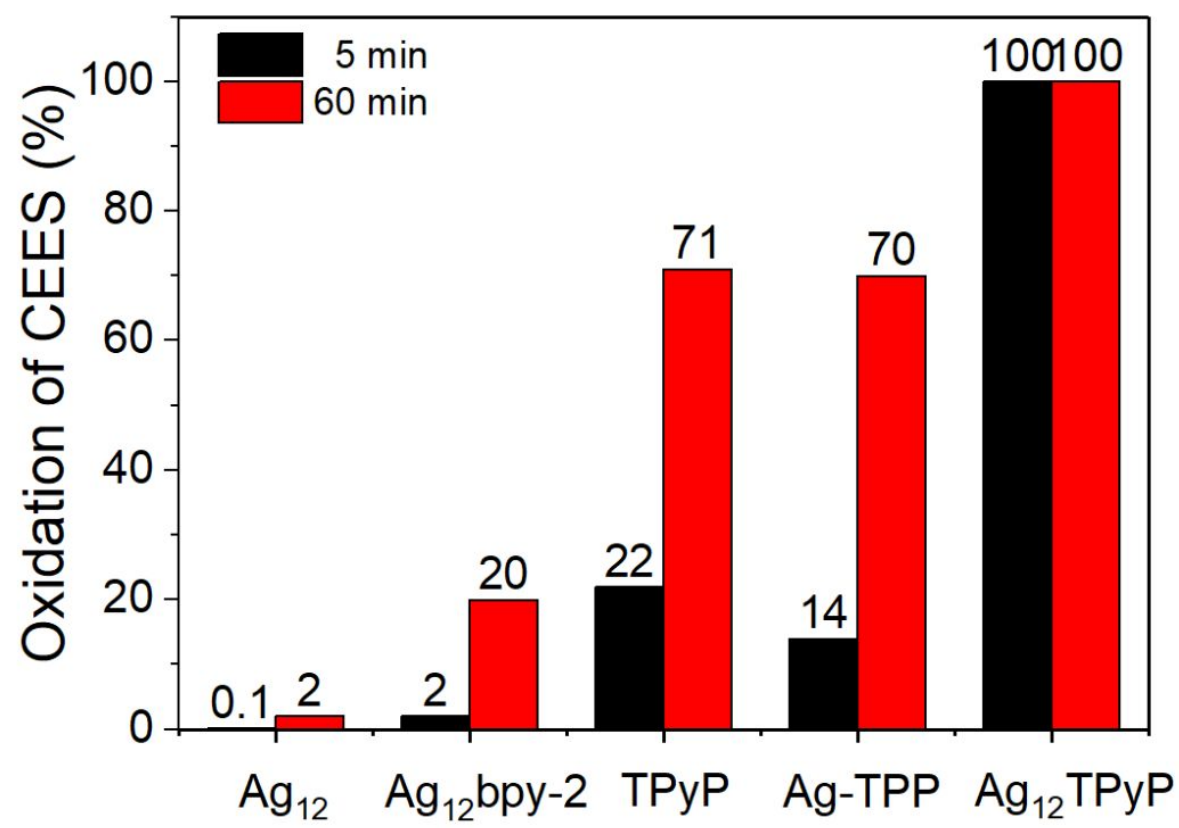

Figure S37. Photooxidation kinetics (oxidation of CEES) of $\mathbf{A g}_{12}, \mathbf{A g}_{12} \mathbf{b p y}-\mathbf{2}, \mathbf{T P y}, \mathbf{A g}-\mathbf{T P P}$ and $\mathbf{A g}_{12}$ TPyP under $\mathrm{O}_{2}$ atmosphere. 


\section{Part S9. Comparison of CEES degradation efficiency using MOF-}

\section{based photosensitizers for singlet oxygen production}

Table S2 summarized the photo-oxidative efficiency of reported MOF materials in CEES detoxification.

Table S2. Comparison of the ability for degrading CEES by using MOF-based photosensitizers with singlet oxygen production

\begin{tabular}{|c|c|c|c|c|c|c|}
\hline catalyst & $\begin{array}{l}\text { catalyst } \\
\text { loading }\end{array}$ & photosensitizer & oxidant & $\begin{array}{l}\text { half-life } \\
\text { (min) }\end{array}$ & $\begin{array}{l}\text { LED type and } \\
\text { Power densities } \\
\left.(\mathrm{mW} \mathrm{cm})^{-2}\right)\end{array}$ & reference \\
\hline PCN-222 & $0.5 \%$ & porphyrin & $\mathrm{O}_{2}$ & $\begin{array}{l}13 \\
26 \\
33\end{array}$ & $\begin{array}{l}\text { blue (325) } \\
\text { white (310) } \\
\text { red (160) }\end{array}$ & S6 \\
\hline NU-1000 & $1 \%$ & pyrene & $\mathrm{O}_{2}$ & 6 & UV (450) & S7 \\
\hline $\begin{array}{l}\text { NU-1000- } \\
\text { PCBA }\end{array}$ & $1 \%$ & $\begin{array}{l}\text { pyrene- } \\
\text { fullerene }\end{array}$ & $\mathrm{O}_{2}$ & 3.5 & UV (450) & S8 \\
\hline $\begin{array}{l}\text { Br-BDP@ } \\
\text { NU-1000 }\end{array}$ & $0.2 \%$ & $\begin{array}{l}\text { pyrene- } \\
\text { BODIPY }\end{array}$ & $\mathrm{O}_{2}$ & $\begin{array}{l}2.5 \\
2\end{array}$ & $\begin{array}{l}\text { green }(325) \\
\text { green }(450)\end{array}$ & S9 \\
\hline UMCM-313 & $0.5 \%$ & perylene & $\mathrm{O}_{2}$ & 4 & UV (2200) & S10 \\
\hline $\mathrm{Ag}_{12} \mathrm{TPyP}$ & $1 \%$ & porphyrin & $\begin{array}{l}\mathrm{O}_{2} \\
\text { Air }\end{array}$ & $\begin{array}{l}1.5 \\
6\end{array}$ & white (80) & Our Work \\
\hline
\end{tabular}




\section{Part S10. Vienna ab initio simulation package (VASP) calculations}

The calculations were performed using the plane-wave-basis-set Vienna ab initio simulation package (VASP). ${ }^{\mathrm{S} 11} \mathrm{~A}$ single K-point at Gamma center was used to sample the Brillouin zone. Projector augmented wave potentials were employed with a kinetic energy cutoff of $425 \mathrm{eV} .^{\mathrm{S} 12}$ For the exchange-correlation function, the Perdew-BurkeErnzerh of generalized gradient approximation was utilized, ${ }^{\mathrm{S} 13}$ and DFT-D2 method was used to evaluate the van der Waals interactions between the organics. ${ }^{\mathrm{S} 14}$ Gaussian smearing with $0.1 \mathrm{eV}$ was used to smooth the occupancy in all the calculations. The structural relaxation was conducted until the forces on each atom were less than 0.01 $\mathrm{eV} / \AA$. The Bader charge partition scheme was adopted to calculate the electron population on each atom. ${ }^{\mathrm{S} 15}$

The density of states (DOS) analysis revealed that the narrower energy gap between HOMO and LUMO of $\mathrm{Ag}_{12}$ TPyP compared with the isolated TPyP ligand facilitates electron photoexcitation and is favorable for the activation of $\mathrm{O}_{2}$ to ${ }^{1} \mathrm{O}_{2}$ (Figure S38). These findings further validated that the assembly of a Ag cluster with the TPyP ligand is beneficial for the rapid photooxidation process.

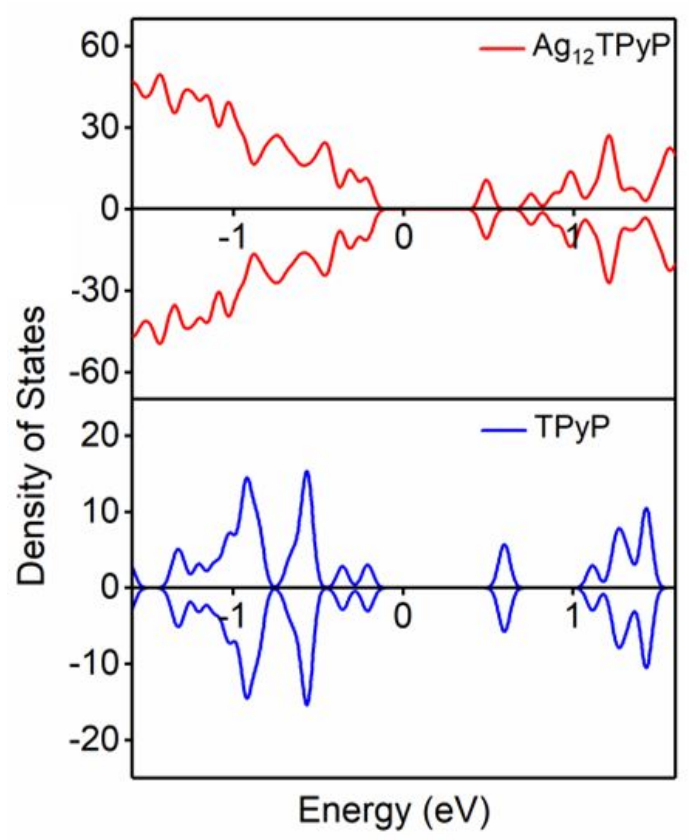

Figure S38. Density of states for $\mathbf{A g}_{12}$ TPyP and TPyP. 


\section{Supplementary References}

S1. R. W. Huang, X. Y. Dong, B. J. Yan, X. S. Du, D. H. Wei, S. Q. Zang, T. C. W. Mak, Angew.Chem. Int. Ed. 2018, 57, 8560-8566.

S2. M. H. So, V. A. L. Roy, Z. X. Xu, S. S. Y. Chui, M. Y. Yuen, C. M. Ho, C. M. Che, Chem. Asian J. 2008, 3, 1968-1978.

S3. G. M. Sheldrick, Acta Crystallogr. Sect. A 2015, 71, 3-8.

S4. O. V. Dolomanov, L. J. Bourhis, R. J. Gildea, J. A. Howard, H. Puschmann, J. Appl. Crystallogr. 2009, 42, 339-341.

S5. G. M. Sheldrick, Acta Crystallogr. Sect. C 2015, 71, 3-8.

S6. Y. Liu, A. J. Howarth, J. T. Hupp, O. K. Farha, Angew. Chem. Int. Ed. 2015, 54, 9001-9005.

S7. Y. Liu, C. T. Buru, A. J. Howarth, J. J. Mahle, J. H. Buchanan, J. B. DeCoste, J. T. Hupp, O. K. Farha, J. Mater. Chem. A 2016, 4, 13809-13813.

S8. A. J. Howarth, C. T. Buru, Y. Liu, A. M. Ploskonka, K. J. Hartlieb, M. McEntee, J. J. Mahle, J. H. Buchanan, E. M. Durke, S. S. Al-Juaid, J. F. Stoddart, J. B. DeCoste, J. T. Hupp, O. K. Farha, Chem. Eur. J. 2017, 23, 214-218.

S9. A. Atilgan, T. Islamoglu, A. J. Howarth, J. T. Hupp, O. K. Farha, ACS Appl. Mater. Interfaces 2017, 9, 24555-24560.

S10. C. T. Buru, M. B. Majewski, A. J. Howarth, R. H. Lavroff, C. W. Kung, A. W. Peters, S. Goswami, O. K. Farha, ACS Appl. Mater. Interfaces 2018, 10, 23802-23806.

S11. G. Kresse, J. Furthmüller, Comp. Mater. Sci. 1996, 6, 15-50.

S12. G. Kresse, D. Joubert, Phys. Rev. B 1999, 59, 1758-1775.

S13. John P. Perdew, Kieron Burke, M. Ernzerhof, Phys. Rev. Lett. 1996, 77, 3865-3868.

S14. S. Grimme, J. Comput. Chem. 2006, 27, 1787-1799.

S15. W. Tang, E. Sanville, G. Henkelman, J. Phys. Condens. Matter. 2009, 21, 084204. 